\title{
Interventions for fatigue in peripheral neuropathy (Review)
}

\author{
White CM, van Doorn PA, Garssen MPJ, Stockley RC
}

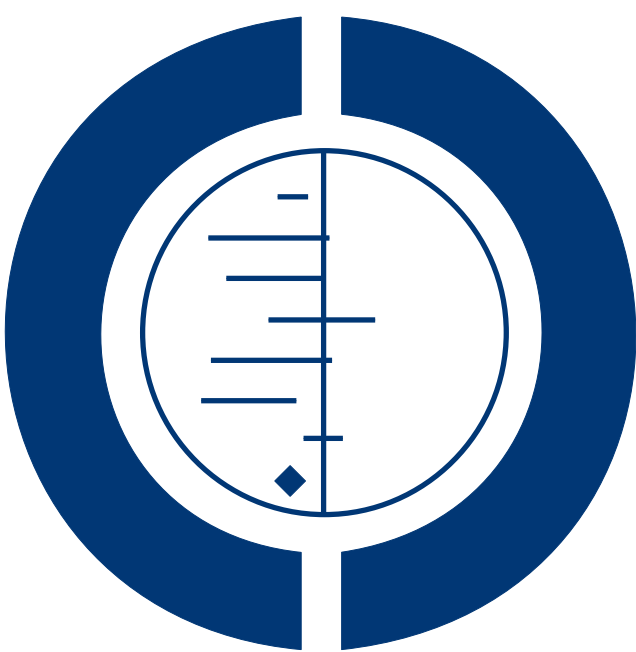

THE COCHRANE COLLABORATION $^{\circledR}$

This is a reprint of a Cochrane review, prepared and maintained by The Cochrane Collaboration and published in The Cochrane Library 2014, Issue 12

http://www.thecochranelibrary.com

\section{WILEY}


TABLE OF CONTENTS

HEADER . . . . . . . . . . . . . . . . . . . . . . . . . . . . . . . . . . 1

ABSTRACT . . . . . . . . . . . . . . . . . . . . . . . . . . . . . . . . . . . . . . . . . . . . . . .

PLAIN LANGUAGE SUMMARY . . . . . . . . . . . . . . . . . . . . . . . . . . . . . . . . . . . .

SUMMARY OF FINDINGS FOR THE MAIN COMPARISON $\quad$. . . . . . . . . . . . . . . . . . . . . . . . . . . 4

BACKGROUND . . . . . . . . . . . . . . . . . . . . . . . . . . . . . . . . . . . . . 6

OBJECTIVES . . . . . . . . . . . . . . . . . . . . . . . . . . . . . . . . . . . . . . . . . . . . .

METHODS . . . . . . . . . . . . . . . . . . . . . . . . . . . . . . . . . . . . . . 7

RESULTS . . . . . . . . . . . . . . . . . . . . . . . . . . . . . . . . . . . . . . . 9

Figure 1. . . . . . . . . . . . . . . . . . . . . . . . . . . . . . . . . . . . . 11

Figure 2. . . . . . . . . . . . . . . . . . . . . . . . . . . . . . . . . . . . . . 13

Figure 3. . . . . . . . . . . . . . . . . . . . . . . . . . . . . . . . . . . . . . 14

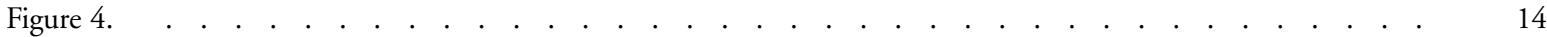

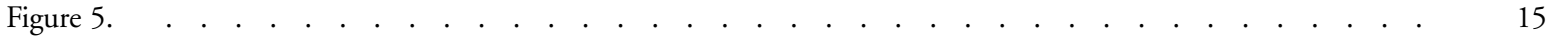

ADDITIONAL SUMMARY OF FINDINGS . . . . . . . . . . . . . . . . . . . . . . . . . . . . . .

DISCUSSION . . . . . . . . . . . . . . . . . . . . . . . . . . . . . . . . . . . . . 19

AUTHORS' CONCLUSIONS . . . . . . . . . . . . . . . . . . . . . . . . . . . . . . . . 21

ACKNOWLEDGEMENTS . . . . . . . . . . . . . . . . . . . . . . . . . . . . . . . . . . . . . . . . .

REFERENCES . . . . . . . . . . . . . . . . . . . . . . . . . . . . . . . . . . . . . . 22

CHARACTERISTICS OF STUDIES . . . . . . . . . . . . . . . . . . . . . . . . . . . . . . . . . . . . . . .

DATA AND ANALYSES . . . . . . . . . . . . . . . . . . . . . . . . . . . . . . . . . . . . . . . . . . . . . . . . . .

ADDITIONAL TABLES . . . . . . . . . . . . . . . . . . . . . . . . . . . . . . . . . . . . . . . . .

WHAT'S NEW .. . . . . . . . . . . . . . . . . . . . . . . . . . . . . . . . . . . . . 34

CONTRIBUTIONS OF AUTHORS . . . . . . . . . . . . . . . . . . . . . . . . . . . . . . . . . 35

DECLARATIONS OF INTEREST . . . . . . . . . . . . . . . . . . . . . . . . . . . . . . . . . . . . . . . . . .

SOURCES OF SUPPORT . . . . . . . . . . . . . . . . . . . . . . . . . . . . . . . . . . . . . .

DIFFERENCES BETWEEN PROTOCOL AND REVIEW . . . . . . . . . . . . . . . . . . . . . . . . . . . . 36

INDEX TERMS . . . . . . . . . . . . . . . . . . . . . . . . . . . . . . . . . . . . 36 


\title{
[Intervention Review] \\ Interventions for fatigue in peripheral neuropathy
}

\author{
Claire M White ${ }^{1}$, Pieter A van Doorn ${ }^{2}$, Marcel PJ Garssen ${ }^{3}$, Rachel C Stockley ${ }^{4}$ \\ ${ }^{1}$ Health \& Social Care Research, Faculty of Life Sciences \& Medicine, King's College London, London, UK. ${ }^{2}$ Department of Neurology, \\ Erasmus University Medical Center, Rotterdam, Netherlands. ${ }^{3}$ Neurology, Jeroen Bosch Hospital And Erasmus Medical Centre, s'- \\ Hertogenbosch, Netherlands. ${ }^{4}$ Physiotherapy, Faculty of Health, Psychology \& Social Care, Elizabeth Gaskell Campus, Manchester, \\ UK
}

Contact address: Claire M White, Health \& Social Care Research, Faculty of Life Sciences \& Medicine, King's College London, Room 3.22, Shepherd's House, Guy’s Campus, London, SE1 1UL, UK. Claire.white@kcl.ac.uk.

Editorial group: Cochrane Neuromuscular Disease Group.

Publication status and date: Edited (no change to conclusions), published in Issue 12, 2014.

Review content assessed as up-to-date: 5 November 2013.

Citation: White CM, van Doorn PA, Garssen MPJ, Stockley RC. Interventions for fatigue in peripheral neuropathy. Cochrane Database of Systematic Reviews 2014, Issue 12. Art. No.: CD008146. DOI: 10.1002/14651858.CD008146.pub2.

Copyright (C) 2014 The Cochrane Collaboration. Published by John Wiley \& Sons, Ltd.

\begin{abstract}
A B S T R A C T
Background

Persistent feelings of fatigue (or subjective fatigue), which may be experienced in the absence of physiological factors, affect many people with peripheral neuropathy. A variety of interventions for subjective fatigue are available, but little is known about their efficacy or the likelihood of any adverse effects for people with peripheral neuropathy.
\end{abstract}

\section{Objectives}

To assess the effects of drugs and physical, psychological or behavioural interventions for fatigue in adults or children with peripheral neuropathy.

\section{Search methods}

On 5 November 2013, we searched the Cochrane Neuromuscular Disease Group Specialized Register, CENTRAL, MEDLINE, EMBASE, CINAHL Plus, LILACS and AMED. We also searched reference lists of all studies identified for inclusion and relevant reviews, and contacted the authors of included studies and known experts in the field to identify additional published or unpublished data. We also searched trials registries for ongoing studies.

\section{Selection criteria}

We considered for inclusion randomised controlled trials (RCTs) and quasi-RCTs comparing any form of intervention for fatigue management in adults with peripheral neuropathy with placebo, no intervention or an alternative form of intervention for fatigue. Interventions considered included drugs, pacing and grading of physical activity, general or specific exercise, compensatory strategies such as orthotics, relaxation, counselling, cognitive and educational strategies.

\section{Data collection and analysis}

Two review authors independently assessed risk of bias and extracted study data. We contacted study authors for additional information. We collected information on adverse events from the included trials.

Interventions for fatigue in peripheral neuropathy (Review)

Copyright $\odot 2014$ The Cochrane Collaboration. Published by John Wiley \& Sons, Ltd. 


\section{Main results}

The review includes three trials, which were all at low risk of bias, involving 530 people with peripheral neuropathy. The effects of amantadine from one randomised, double-blind, placebo-controlled, cross-over trial comparing amantadine with placebo for the treatment of fatigue in 80 people with Guillain-Barré syndrome (GBS) were uncertain for the proportion of people achieving a favourable outcome six weeks post-intervention (odds ratio (OR) 0.56 (95\% confidence interval (CI) 0.22 to $1.35, \mathrm{~N}=74, \mathrm{P}=0.16$ ). We assessed the quality of this evidence as low. Two parallel-group randomised double-blind, placebo-controlled trials comparing the effects of two doses of ascorbic acid with placebo for reducing fatigue in adults with Charcot-Marie-Tooth disease type 1A (CMT1A) showed that the effects of ascorbic acid at either dose are probably small (standardised mean difference (SMD) -0.12 (95\% CI -0.32 to 0.08 , $\mathrm{n}=404$, $\mathrm{P}=0.25)$ ) for change in fatigue after 12 to 24 months (moderate quality evidence). Neither ascorbic acid study measured fatigue at four to 12 weeks, which was our primary outcome measure. No serious adverse events were reported with amantadine. Serious adverse events were reported in the trials of ascorbic acid. However,risk of serious adverse events was similar with ascorbic acid and placebo.

\section{Authors' conclusions}

One small imprecise study in people with GBS showed uncertain effects of amantadine on fatigue. In two studies in people with CMT1A there is moderate-quality evidence that ascorbic acid has little meaningful benefit on fatigue. Information about adverse effects was limited, although both treatments appear to be well tolerated and safe in these conditions.

There was no evidence available from RCTs to evaluate the effect of other drugs or other interventions for fatigue in either GBS, CMT1A or other causes of peripheral neuropathy. The cost effectiveness of different interventions should also be considered in future randomised clinical trials.

\section{PLAIN LANGUAGE SUMMARY}

Treatments for fatigue in peripheral neuropathy

\section{Review question}

To assess the effects of treatments for fatigue in people with peripheral neuropathy.

\section{Background}

Peripheral neuropathy is damage to the nerves outside the brain and spinal cord. Many people with peripheral neuropathy have feelings of severe tiredness (fatigue) that are not necessarily related to physical problems such as muscle weakness. Evidence in other long-term illnesses where fatigue is a problem suggests that medicines and other forms of treatment may help. The aim of this review was to assess the effect of drugs and other treatments, such as general or specific exercise, orthotics (devices such as braces), relaxation, counselling and cognitive, behavioural and educational strategies on feelings of fatigue in people with peripheral neuropathy.

\section{Study characteristics}

From a wide search, we identified three RCTs that met our selection criteria. The trials involved a total of 530 adults with peripheral neuropathy. Treatments were ascorbic acid (vitamin C) in people with Charcot-Marie-Tooth disease in two trials, and amantadine in Guillain-Barré syndrome in the third. Charcot-Marie-Tooth disease is an inherited nerve disease and Guillain-Barré syndrome is a condition where there is inflammation of the peripheral nerves. We chose measures of fatigue at four to 12 weeks as our preferred measure of the effects of treatment. The amantadine trial but not the ascorbic acid trials provided data at this time point; the ascorbic acid trials provided data more than 12 months after the start of the intervention.

\section{Key results and quality of the evidence}

There was insufficient evidence to determine the effects of amantadine when compared with an inactive treatment (placebo) for fatigue. and there were no major unwanted effects. We found evidence that ascorbic acid probably has little meaningful benefit for fatigue. No major unwanted effects were identified, but the trials were small. We assessed the quality of this evidence as moderate because the results were imprecise, which means they do not rule out the possibility that the drugs could have an effect. We found no evidence from RCTs on other medicines or treatments for fatigue in peripheral neuropathy.

There is insufficient evidence to determine the effect of amantadine for fatigue in GBS and ascorbic acid for fatigue in CMT1A. More high-quality studies are needed to provide evidence on which to base management of feelings of fatigue in peripheral neuropathy. The cost effectiveness of different interventions should also be considered in future RCTs.

Interventions for fatigue in peripheral neuropathy (Review)

Copyright $\odot 2014$ The Cochrane Collaboration. Published by John Wiley \& Sons, Ltd. 
The evidence in this review is current to November 2013.

Copyright $\odot 2014$ The Cochrane Collaboration. Published by John Wiley \& Sons, Ltd. 


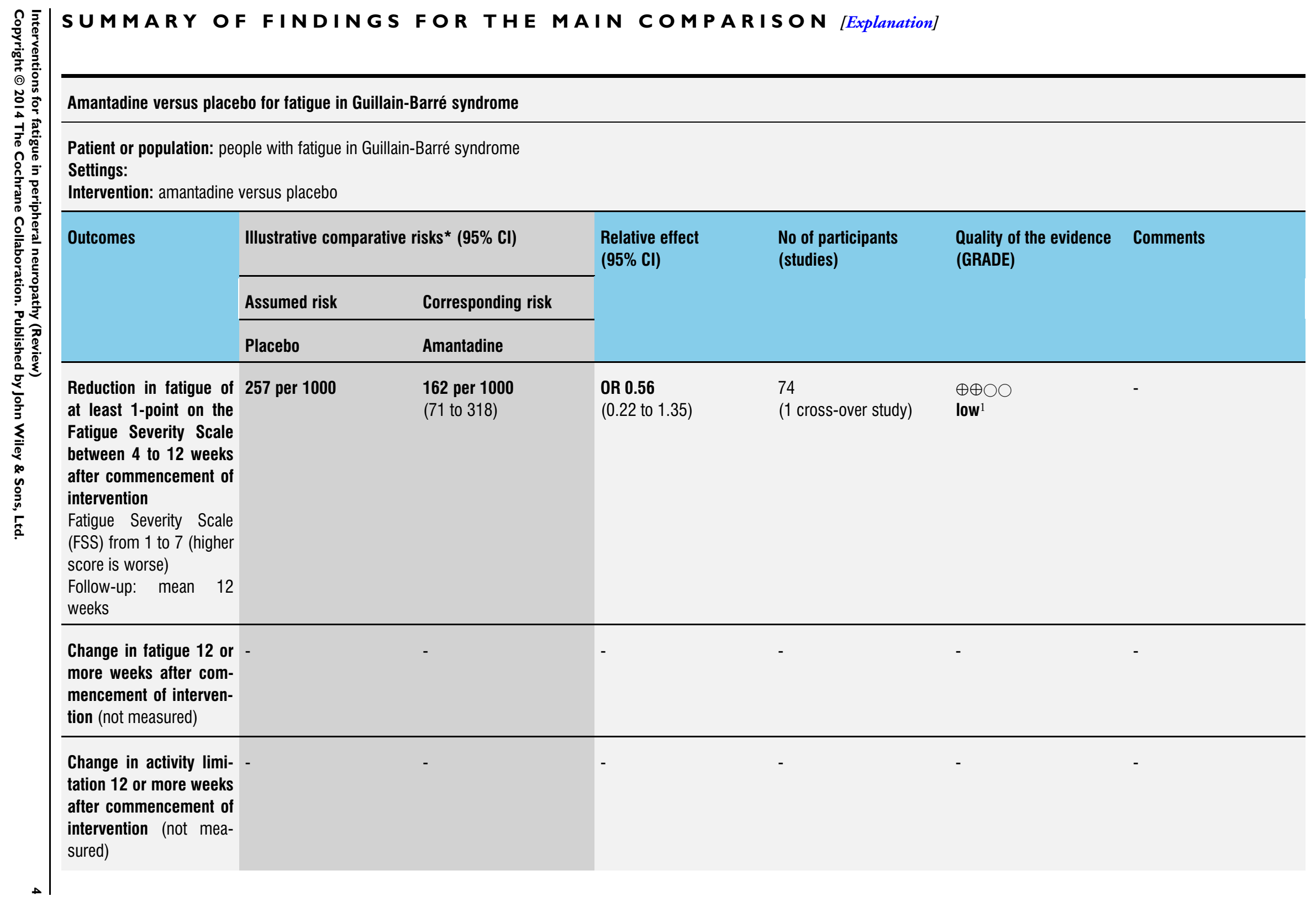


Change in participation The mean change in par- The mean change in par-

12 or more weeks after ticipation 12 or more ticipation 12 or more

commencement of inter- weeks after commence- weeks after commence-

vention using the ment of intervention using ment of intervention us-

Rotterdam Hand- the control group was ing the intervention group

icap Scale. Scale from: $0 \mathbf{0 . 3 4}$ points

to 36 .

Follow-up: mean 12

weeks

Health related quality of

life after 12 or more

weeks or more after

commencement of inter-

vention (not reported)

\begin{tabular}{|c|c|c|c|c|c|c|}
\hline Serious adverse events & See comment & See comment & Not estimable & 80 & See comment & 0 participants had seri- \\
\hline $\begin{array}{l}\text { Follow-up: mean } 12 \\
\text { weeks }\end{array}$ & & & & (1 cross-over study) & & $\begin{array}{l}\text { ous adverse events in this } \\
\text { study }\end{array}$ \\
\hline
\end{tabular}

*The basis for the assumed risk (e.g. the median control group risk across studies) is provided in footnotes. The corresponding risk (and its $95 \%$ confidence interval) is based on the assumed risk in the comparison group and the relative effect of the intervention (and its $95 \% \mathrm{Cl}$ ).

Cl: confidence interval; RR: risk ratio; OR: odds ratio

GRADE Working Group grades of evidence

High quality: Further research is very unlikely to change our confidence in the estimate of effect.

Moderate quality: Further research is likely to have an important impact on our confidence in the estimate of effect and may change the estimate.

Low quality: Further research is very likely to have an important impact on our confidence in the estimate of effect and is likely to change the estimate.

Very low quality: We are very uncertain about the estimate.

${ }^{1}$ Evidence downgraded two levels due to imprecision (small sample size and wide $\mathrm{Cl}$ that crosses the line of no effect)
EHQ and SF-36 measured

but data not fully reported

0.31 higher

(0.09 lower to 0.72

higher) $\begin{array}{ll}74 & \oplus \oplus \bigcirc \bigcirc \\ \text { (1 cross-over study) } & \text { low }^{1}\end{array}$ 


\section{B A C K G R O U N D}

\section{Description of the condition}

Peripheral neuropathies collectively affect about $2.4 \%$ of the population and may be either genetic or acquired, and either acute or chronic in nature (Martyn 1998). The pathological process affects peripheral nerves, resulting in neurological damage to either the axon (ie, degeneration of the central nerve fibre), the myelin (ie, demyelination or destruction of the insulating sheath of the nerve), or a combination of both. Recovery may be by remyelination, through which improvements in function can be rapid, and in some people there is almost complete recovery. However, regeneration of damaged axons usually takes many months or years and recovery, if present, may be incomplete (Tamura 2007).

Common symptoms of peripheral neuropathy include numbness, diminished or altered sensation (pins and needles), muscle weakness, and autonomic dysfunction. People may also experience fatigue, pain, psychological dysfunction and poor social adjustment (Lennon 1993; Pfeiffer 2001). Even when neurological function improves, residual symptoms often persist and fatigue is frequently an ongoing problem (Merkies 1999).

The experience of fatigue (or subjective fatigue) has been described as a "an overwhelming sense of tiredness, lack of energy and feeling of exhaustion" that is "not relieved by rest" and is a common sequel of chronic conditions (Bleijenberg 2003; Karlsen 1999; Krupp 2003). Physiological fatigue, or "the loss of voluntary force-producing capacity during exercise" (Bigland-Ritchie 1978) can contribute to subjective fatigue, but people can experience subjective fatigue in the absence of physiological factors and physiological fatigue does not necessarily result in subjective fatigue.

Physical factors such as residual muscle weakness mean that people with peripheral neuropathy have to work harder during everyday activities than healthy individuals, which will feel more of an effort. Axonal degeneration prevents nerve impulses from being conducted along the peripheral nerve and demyelination can lead to conduction block that can be exacerbated by muscle activity (Cappelen-Smith 2000), leading to fatigue (Kaji 2000). Although there is no direct problem with the muscles themselves, it has been shown that people with peripheral neuropathy may be unable to voluntarily activate their muscles fully, possibly because of dysfunction within the central nervous system (Garssen 2007; Schillings 2003). This form of physiological fatigue is known as central fatigue and could possibly be due to reduced drive from nerve cells in the brain (cortical neurons) or to the effect of alterations in the number of surviving peripheral nerve axons and an increase in the number of muscle fibres they innervate (Martinez-Figuerora 1977; Sanders 1996). In addition, psychological factors such as lack of motivation or low mood can also affect voluntary activation of muscles (Gandevia 2001; Kent-Braun 1993). Fear of precipitating fatigue may also contribute and lead to an avoidance of physical activity and physical deconditioning, thus further exacerbating fatigue (Moss-Morris 2005). Environmental factors may also precipitate fatigue, since many people with peripheral neuropathies have to utilise compensatory strategies such as orthoses or walking aids as a result of deformities or sensory deficits. Therefore, the experience of fatigue may be clearly related to known underlying factors or, more commonly, be only partly explained by these. Finally, measurement of the level of fatigue is difficult both because the subjective experience of fatigue varies between individuals and because measures of different types of fatigue are numerous.

\section{Description of the intervention}

The evidence about the efficacy of interventions for fatigue in peripheral neuropathy and other chronic conditions is limited and unclear. Interventions aim to address physical, environmental and psychological factors contributing to fatigue, and include drugs, pacing and grading of physical activity, general or specific exercise, orthotics, relaxation, counselling, cognitive behavioural strategies and others.

\section{How the intervention might work}

The presumed mode of action of drug interventions such as amantadine for generalised fatigue is unknown (Pucci 2009); one randomised controlled trial (RCT) showed no effect in inflammatory peripheral neuropathy (Garssen 2006). It is likely that factors contributing to subjective fatigue in individuals with peripheral neuropathy must be clearly understood in order to target interventions effectively. For example, where fatigue is due to weakness, strengthening exercise may be beneficial, but where altered mood or well-being is a factor then drug, cognitive or behavioural interventions may be more relevant. It is likely that multidimensional interventions that address individuals' self perception and health beliefs combined with strategies to increase levels of physical activity or participation in regular exercise or both may also be helpful.

\section{Why it is important to do this review}

Fatigue is a frequent and often severe problem that affects everyday activities and quality of life for people with peripheral neuropathy. Although there have been some RCTs of drug and non-drug interventions for fatigue in peripheral neuropathy, we know of no systematic review.

\section{O B J E C T IVES}


To assess the effects of drugs and physical, psychological or behavioural interventions for fatigue in adults or children with peripheral neuropathy.

\section{METHODS}

\section{Criteria for considering studies for this review}

\section{Types of studies}

We included all randomised controlled trials (RCTs) or quasiRCTs of any drug or non-drug intervention to treat fatigue associated with peripheral neuropathy, compared with placebo, no treatment or other drug or non-drug interventions for fatigue. Quasi-RCTs are those in which randomisation was intended but they use methodology that may be biased, such as alternation, or use of case record numbers or date of birth.

\section{Types of participants}

We considered for inclusion in the review all trials in which participants (adults or children) had fatigue associated with a diagnosis of peripheral polyneuropathy, including sensory, motor and combined sensory and motor neuropathies. We did not consider trials including mostly people with focal disease such as local entrapment neuropathies with pain as the primary presenting feature (for example, cervical radiculopathy, carpal tunnel syndrome, brachial plexus neuritis, etc), and poliomyelitis. We accepted the diagnosis of peripheral neuropathy offered by the study authors, provided that it stipulated the presence of clinical impairment characteristic of peripheral neuropathy. We did not include diagnoses dependent on symptoms suggestive of neuropathy alone or neurophysiological abnormalities in the absence of clinical signs.

\section{Types of interventions}

We considered trials including any form of intervention for fatigue management, such as drugs, pacing and grading of physical activity, general or specific exercise, compensatory strategies such as orthotics, relaxation, counselling, cognitive and educational strategies and others, compared with either placebo, no intervention or an alternative form of intervention for fatigue.

\section{Types of outcome measures}

\section{Primary outcomes}

Our primary outcome was fatigue severity and symptoms as measured by any validated scale evaluated at least four weeks and less than 12 weeks after commencement of the intervention. Where studies used more than one scale, we used the preferred ranking of commonly-used scales shown below to identify the scale to be used in the primary outcome analysis. Instruments that we considered appropriate included: Fatigue Severity Scale (FSS) (Krupp 1989), Chalder Fatigue Scale (Chalder 1993), Fatigue Impact Scale or daily-FIS (D-FIS) (Fisk 1994; Fisk 2002), Visual Analogue Scale of Fatigue (VAS-F) (Lee 1991), and Piper Fatigue Scale (PFS) (Piper 1998).

\section{Secondary outcomes}

1. Fatigue after 12 or more weeks.

2. Activity limitations after 12 or more weeks.

3. Participation restrictions after 12 or more weeks.

4. Health-related quality of life after 12 or more weeks.

5. Adverse events: any adverse events, adverse events which lead to discontinuation of treatment and serious adverse events, which are those which are fatal, life-threatening, or require prolonged hospitalisation.

\section{Search methods for identification of studies}

\section{Electronic searches}

On 5 November 2013, we searched the Cochrane Neuromuscular Disease Group Specialized Register, the Cochrane Central Register of Controlled Trials (CENTRAL) (2013, Issue 10), MEDLINE (January 1966 to October 2013), EMBASE (January 1980 to October 2013), LILACS (January 1982 to October 2013), CINAHL Plus (January 1937 to October 2013) and AMED (January 1985 to October 2013). The detailed search strategies are in the appendices: Appendix 1 (MEDLINE), Appendix 2 (EMBASE), Appendix 3 (CINAHL Plus), Appendix 4 (CENTRAL), Appendix 5 (AMED), Appendix 6 (LILACS) and Appendix 7 (the Cochrane Neuromuscular Disease Group Specialized Register).

On 12 June 2014 we searched the Current Controlled Trials register (www.controlled-trials.com), ClinicalTrials.gov ( www.clinicaltrials.gov) and the WHO International Clinical Trials Registry Platform (ICTRP) (www.who.int/ictrp/en/), using the search terms 'fatigue' and 'peripheral neuropathy'.

\section{Searching other resources}

We reviewed the bibliographies of the randomised trials identified, contacted the trial authors and known experts in the field, and approached pharmaceutical companies to identify additional published or unpublished data.

\section{Data collection and analysis}




\section{Selection of studies}

Two review authors (CMW, RCS) independently examined the titles and abstracts identified by the search. There were no language restrictions. We obtained English language translations where appropriate. We retrieved all trials that were relevant and reviewed full-text publications. We examined retrieved publications against the selection criteria and we resolved any disagreement by consensus. We did not have to resort to arbitration by a third author (MPG). If trials had had a heterogenous sample of disorders, we would have only included them if data from participants with peripheral neuropathy could be isolated or if at least $75 \%$ of the participants had peripheral neuropathy.

\section{Data extraction and management}

For each retrieved publication, two review authors (CW and RCS) independently extracted the relevant data using standardised forms. We resolved any disagreements by discussion. We gathered data on:

- eligibility criteria;

- interventions;

- details of participants;

- assignment to groups;

- outcome measures;

- time at which outcomes are measured;

- funding;

- declarations of interest;

- sample size; and

- statistical analysis.

\section{Assessment of risk of bias in included studies}

Two out of three review authors (CW, RS and MG) independently assessed all included studies for risk of bias. We graded the items according to the Cochrane Handbook for Systematic Reviews of Interventions (Higgins 2011a) and presented our assessments in a 'Risk of bias' table. We assessed trials for random sequence generation, allocation concealment, blinding (participants, personnel and outcome assessors), incomplete outcome data, selective outcome reporting and other potential sources of bias.

We then made a judgement on each of these criteria relating to the risk of bias, of 'low risk of bias', 'high risk of bias' or 'unclear risk of bias'.

\section{Measures of treatment effect}

\section{Continuous data}

For studies using the same outcome measures, we summarised continuous data using mean differences (MDs), sometimes called 'weighted mean differences', with a corresponding 95\% confidence interval (CI). When different studies measured the same outcome in different ways we analysed results using standardised mean differences (SMDs) with a 95\% CI.

\section{Dichotomous data}

For studies using similar outcomes with dichotomous data we calculated a pooled estimate of the risk ratio (RR), with a 95\% CI.

\section{Unit of analysis issues}

Where there were multiple intervention groups within a trial, we made pairwise comparisons of similar interventions or active components versus no treatment, placebo, or another intervention. We planned to analyse cross-over trials with continuous outcome measures using generalised inverse variance analysis (GIV) (DerSimonian 1986), where the estimated difference in the mean treatment effects and their standard errors were available for pooling with equivalent results from parallel-group studies. If this information had not been available then we would have pooled data from the first phase only, where possible, with parallel design studies. For cross-over studies with dichotomous outcomes we would have pooled results using odds ratios (ORs) and confidence intervals from paired analyses where available (Elbourne 2002). Only one cross-over trial was included for any comparison, so no decisions about pooling data were necessary. We would have reported trials with unique designs or outcomes without a meta-analysis. We excluded studies that were not RCTs from the analyses but we comment on them in the Discussion.

\section{Dealing with missing data}

For all outcomes, where continuous data were presented as mean change with 95\% CIs, the standard deviations (SDs) were calculated for input into analyses and forest plots assuming a normal distribution due to a moderate sample size, using the equation SD = SQRT of number of participants X (upper limit of CI to lower limit of CI) / 3.92. as recommended in Section 7.7.3.2 of the Cochrane Handbook for Systematic Reviews of Interventions (Higgins 2011b). Where overall disability sum score (ODSS) data were presented as median and interquartile ranges, we did not input any data for analysis. Where participant dropout led to missing data we contacted trial authors if an intention-to-treat analysis had not been performed. We also contacted authors where there were missing data for review outcomes, and additional data were provided for the secondary outcome of participation in one study (Garssen 2006).

\section{Assessment of heterogeneity}

We undertook meta-analysis when studies investigated similar interventions, used similar outcome measures and included groups of participants who were clinically homogeneous. Where studies were heterogeneous for some outcomes we undertook a narrative review. 
If studies were similar in intervention, outcome measurement and participants, we assessed possible inconsistency across studies using the $\mathrm{I}^{2}$ statistic (Higgins 2003; Higgins 2011a). If studies had been heterogeneous ( $\mathrm{Q}$ statistic $=0.1$ and $\mathrm{I}^{2}$ statistic of $25 \%$ or greater), the review authors would have considered conducting subgroup analysis only. If we had considered the primary studies to be heterogeneous even within subgroups, we would have undertaken a narrative approach rather than a meta-analysis.

\section{Assessment of reporting biases}

We did not use funnel plots to investigate associations between effect size and study precision in terms of sample size, because of the small number of studies included in the review. If we had included funnel plots, we would have explored the relationships observed to investigate differences between studies with large and small samples, or systematic biases, such as publication bias.

\section{Data synthesis}

For studies with a similar type of intervention or a similar active component, we performed a meta-analysis to calculate a treatment effect across trials with a fixed-effect model, as heterogeneity was not demonstrated. Dichotomous outcome results were available from only one study so we did not present pooled RRs. Where it was not possible to perform a meta-analysis we provided descriptive summaries of the results from each trial.

\section{'Summary of findings' table}

We created 'Summary of findings' tables using the following outcomes:

1. Fatigue severity and symptoms between four and 12 weeks after commencement of the intervention.

2. Fatigue after 12 or more weeks.

3. Activity limitations after 12 or more weeks.

4. Participation restrictions after 12 or more weeks.

5. Health-related quality of life after 12 or more weeks.

6. Serious adverse events.

We used the five GRADE considerations (study limitations, consistency of effect, imprecision, indirectness and publication bias) to assess the quality of a body of evidence (studies that contribute data) for the prespecified outcomes. We used methods and recommendations described in Chapters 11 and 12 of the Cochrane Handbook for Systematic Reviews of Interventions (Schünemann 2011a; Schünemann 2011b). We used GRADEpro software (GRADEpro 2008). We explained decisions to down- or up-grade the quality of studies using footnotes and we made comments to aid reader's understanding of the review where necessary.

\section{Subgroup analysis and investigation of heterogeneity}

Insufficient data available. See Appendix 8 for methods planned but not implemented.

\section{Sensitivity analysis}

Insufficient data available. See Appendix 8 for methods planned but not implemented.

This review has a protocol (White 2009). We listed any deviations from the protocol in Differences between protocol and review.

\section{RES U L T S}

\section{Description of studies}

See Characteristics of included studies and Characteristics of excluded studies for details.

The electronic and manual searches identified a total of 1386 titles and abstracts. After removing duplicates and excluding abstracts where studies were clearly not eligible for inclusion, only six full publications, four protocols and two abstracts were relevant to the review. After reading the full text of the six published articles we excluded three: two were not randomised controlled trials (RCTs) (Carter 2006; Enderlin 2008) and one was an RCT of ascorbic acid for children with CMT1A in which fatigue was not an outcome (Burns 2009). We included one abstract of conference proceedings, regarding an RCT of a new low-dose combination of three already approved drugs for CMT1A, as an ongoing trial, as the analyses are ongoing (Attarian 2013). We will include this study in future updates of this review if appropriate. Two of the other five ongoing or unpublished studies were RCTs of ascorbic acid in CMT1, and we contacted the authors for further information (NCT00484510; Verhamme 2009). However, in these ongoing studies, fatigue was not included as an outcome and we excluded them. One randomised trial of coenzyme Q10 for CMT (NCT00541164), with changes in weakness, fatigue and pain as the primary outcome, is completed but appears to be unpublished. NCT02121678 is not yet recruiting, but will study resistance training for chronic inflammatory demyelinating neuropathy (CIDP) with the fatigue severity scale (FSS) as a planned secondary outcome. We identified one study, Ramdharry 2011, from an abstract in the Cochrane Neuromuscular Disease Group Specialized Register. The study appears to be ongoing and the authors provided no data when contacted. We will include it if eligible once the full publication is available. See Characteristics of ongoing studies.

The study selection process therefore resulted in only three trials finally meeting the criteria for inclusion (Garssen 2006; Micallef 2009; Pareyson 2011).

\section{Study design and participants}

We include three studies evaluating the efficacy of two drugs for fatigue in two different populations (Garssen 2006; Micallef 2009; Pareyson 2011). 
The first study (Garssen 2006) was a randomised, double-blind, placebo-controlled, cross-over trial of amantadine for severe fatigue in 80 neurologically well-recovered participants who had had Guillain-Barré syndrome (GBS). Randomisation was in blocks of six with half the study participants receiving amantadine first and the remainder receiving placebo first. Interventions were followed by a two-week washout period. Assessment of outcomes occurred on six occasions: 1: at baseline, 2: following two weeks of no intervention, 3: after six weeks of intervention 1, 4: after a two-week washout period, 5: after six weeks of intervention 2, and finally 6: after a further two-week washout period. Three randomised participants were withdrawn from the study in the pre-cross-over phase. One participant was in the placebo group and withdrew because of concern over potential side effects of amantadine when she became pregnant. The two other participants were in the amantadine treatment group; one withdrew because of hospital admission with acute cholangitis and the second participant developed severe complaints of dizziness. A further three participants were excluded from the analysis due to incorrect completion of the FSS. Therefore, 74 participants with GBS were included in the reporting of outcomes. All participants had been diagnosed with GBS between six months and 15 years previously and had no apparent changes in GBS disability score for the three months prior to entering the study. All could walk at least 10 metres with or without a walking aid (GBS disability score < 3).

The two remaining studies (Micallef 2009; Pareyson 2011) were parallel-group, randomised, double-blind, placebo-controlled trials of the effect of ascorbic acid in a total of 450 adults with Charcot-Marie-Tooth disease type 1A (CMT1A). In one, two doses (either $1 \mathrm{~g}$ or $3 \mathrm{~g}$ daily) of ascorbic acid or placebo were used in the treatment of 179 participants (Micallef 2009). Confirmation of diagnosis was by clinical examination and genotyping with duplication in $17 \mathrm{p} 11.2$ and at least one motor sign or symptom (gait disorder, distal amyotrophy, foot deformation or distal weakness). Block randomisation into three groups with matching for study site and sex was followed by 12 months of treatment with either $1 \mathrm{~g}$ or $3 \mathrm{~g}$ of ascorbic acid or placebo; outcomes were assessed at baseline and after 12 months of intervention. A total of 16 participants withdrew from the study after randomisation due to adverse events (six), withdrawal of consent (six), loss to follow-up (two), non-compliance (one) or missing baseline data (one).

Therefore, 163 participants completed the study but analysis was of all 179 participants, on an intention-to-treat basis.

In the second multicentre study (Pareyson 2011), the efficacy of chronic administration, for 24 months, of either $1.5 \mathrm{~g} /$ day ascorbic acid or placebo in the treatment of 271 participants (eligible for analysis) with Charcot-Marie-Tooth disease 1A was evaluated. Participants had a clinical diagnosis of Charcot-Marie-Tooth disease $1 \mathrm{~A}$ with genetic confirmation of $17 \mathrm{p} 11.2$-p12 duplication and a CMT neuropathy score of between 1 (excluding the electrophysiological component) and 35 (including the electrophysiological component). Block randomisation of 277 participants into groups of four stratified by disease severity and centre was followed by 24 months of treatment with either ascorbic acid or placebo, and outcomes were assessed at six-monthly intervals from commencement of intervention until 24 months. Six participants did not receive the allocated intervention after randomisation, and are dropped from the denominators. A total of 22 participants withdrew from the intervention after commencement. Reasons for withdrawal were adverse events (13), withdrawal of consent (six), moved away from study area (two) or for personal reasons (one). Whilst the primary study outcome was based on all randomised patients who received at least one dose of the study drug using imputation for missing data the secondary analyses were conducted without imputation of missing data.

\section{Interventions}

The study of amantadine in Guillain-Barré syndrome was a crossover trial in which amantadine was compared with placebo at a dose of one tablet $(100 \mathrm{mg})$ daily for one week followed by two tablets daily for the remaining five weeks of each intervention period. A washout period of two weeks was incorporated before the participants shifted to the other treatment arm (amantadine or placebo) (Garssen 2006).

The studies of ascorbic acid in Charcot-Marie-Tooth disease $1 \mathrm{~A}$ were a parallel-group study comparing $1 \mathrm{~g}$ or $3 \mathrm{~g}$ of ascorbic acid in a single administration of three capsules with three placebo capsules for 12 months (Micallef 2009) and a parallel-group study comparing $1.5 \mathrm{~g}$ of ascorbic acid in two daily doses with placebo tablets for 24 months (Pareyson 2011).

\section{Outcomes}

In participants with severe fatigue due to Guillain-Barré syndrome (defined as Fatigue Severity Scale (FSS) 5.0 or more; FSS range 1 to 7), Garssen 2006 used a reduction of at least one point on the FSS as a primary outcome measure of fatigue. Outcomes for FSS were reported for both phases of the cross-over study. Secondary outcome measures in the major domains of the International Classification of Functioning, Disability and Health (ICF) were: for structure and function, anxiety and depression using the Hospital Anxiety and Depression Scale (HADS); for activity, impact of fatigue using the Fatigue Impact Scale (FIS); and for participation, Rotterdam Handicap Scale (RHS), quality of life using the Medical Outcomes Short Form-36 (SF-36) Health Survey and the Euroquol Health Questionnaire (EQHQ); and adverse events. In the studies of ascorbic acid in participants with Charcot-MarieTooth disease 1A, the primary outcome was CMT neuropathy score (CMTNS). Fatigue was assessed as a secondary outcome using the change in Visual Analogue Scale - Fatigue (VAS-F), either 12 months (Micallef 2009) or 24 months (Pareyson 2011) after commencement of the intervention. Secondary outcomes of activity limitation using the Overall Disability Sum Score (ODSS) (Micallef 2009) or Overall Neuropathy Limitations Scale (ONLS) 
(Pareyson 2011), 10 metre walk test (10MWT) Pareyson 2011 and 9 hole peg test (9HPT) (Pareyson 2011) were reported, as well as measures of participation and quality of life using the SF36 and adverse events in both studies.

\section{Risk of bias in included studies}

See Characteristics of included studies for details and Figure 1.

Figure I. Methodological quality summary: review authors' judgements about each methodological quality item for each included study. Key: green $(+)=$ low risk of bias; yellow (?) = unclear risk of bias; red $(-)=$ high risk of bias.

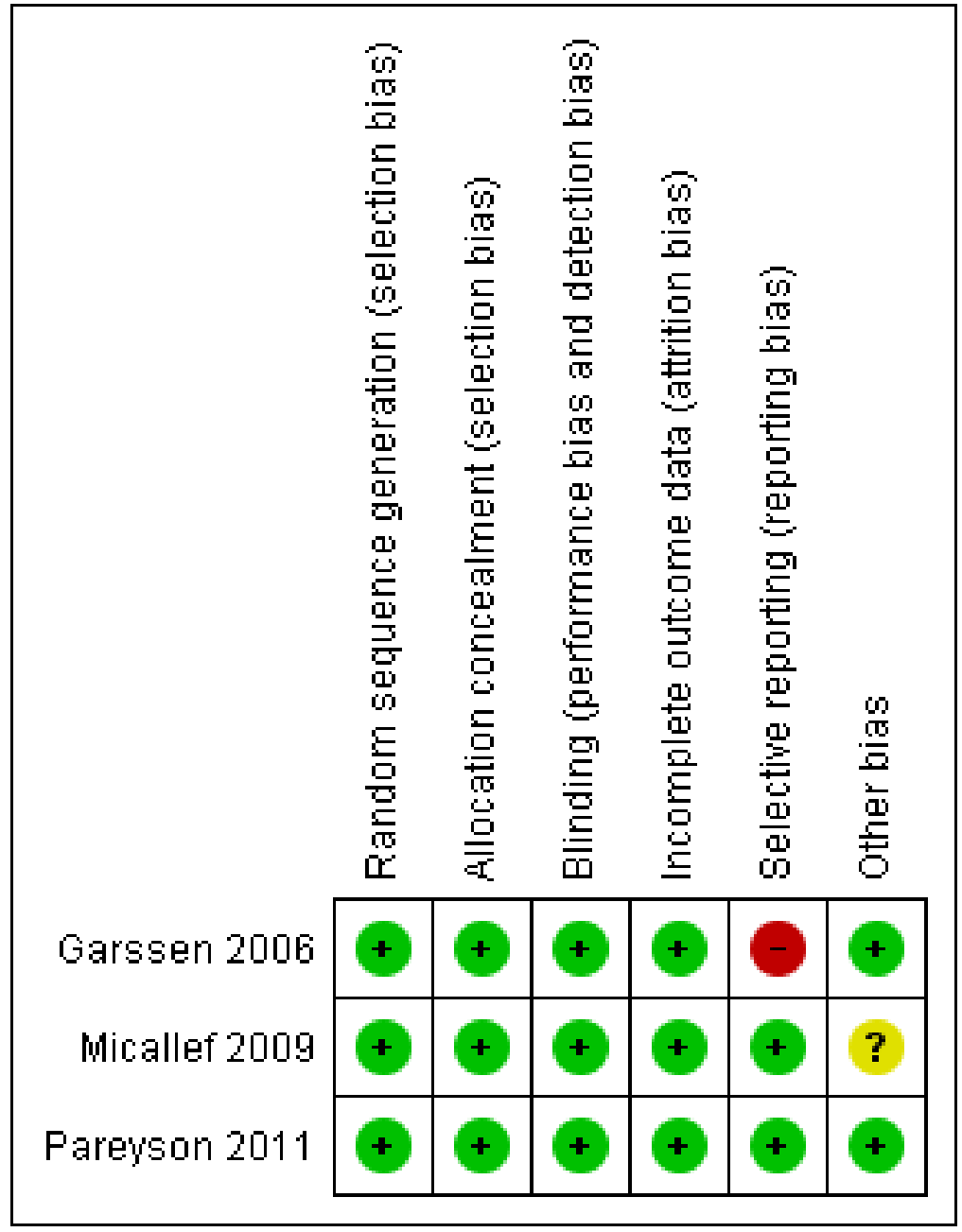


Garssen 2006 conducted block randomisation in blocks of six, although allocation was concealed from researchers; we therefore considered the study to be at low risk of bias for these criteria. The trial was a double-blind, placebo-controlled study, with 80 participants initially enrolled. Although the final analysis was based on 74 participants as six were withdrawn, there was adequate reporting of the loss to follow-up. Sample size was calculated using estimates of proportion from unpublished data obtained from a pilot study, indicating that 36 participants per group were required for $90 \%$ power at a two-sided 5\% alpha, so that with 77 participants completing the trial it was sufficiently powered to detect a difference. The washout period of two weeks between cross-over intervention phases seems sufficient to avoid a carry-over effect of amantadine, and is comparable with other randomised controlled cross-over designs of efficacy for amantadine in other populations (Cohen 1989; Pucci 2009; Rosenberg 1988). The authors reported data for mean (SD) improvement in FSS scores for both amantadine and placebo treatment in both the amantadine-placebo (0.46 (1.29), $\mathrm{P}$ $=0.078 ; 95 \% \mathrm{CI}-0.92$ to 0.05$)$ and placebo-amantadine sequence (0.08 (1.44), $\mathrm{P}=0.28 ; 95 \% \mathrm{CI}-1.24$ to 0.44$)$ groups and t-test analysis for period effects and carry-over effects were not significant. There was some evidence of selective reporting of secondary outcomes, as only P values were reported. Overall we considered the study to be at low risk of bias.

In Micallef 2009, sequence generation was conducted by an independent contract research organisation who were also responsible for concealed allocation of randomisation into blocks of 12 that were stratified for sex and study site (three sites). The trial was double-blind with the administration of visually identical hard gelatin capsules for all groups. Analysis was on an intention-to-treat basis with 179 participants randomised and analysed despite 15 withdrawals prior to follow-up (four from the placebo group, eight from the $1 \mathrm{~g}$ ascorbic acid group and three from the $3 \mathrm{~g}$ ascorbic acid group); one participant from the placebo group had missing baseline data for the study's primary outcome. All study outcomes were adequately reported. Whilst authors stated that the data were analysed on an intention-to-treat basis there was no indication of how the investigators dealt with the missing data from 16 participants. Our overall summary assessment was that the study was at low risk of bias.

In the third study (Pareyson 2011), an independent randomisation unit was responsible for sequence generation and group allocation stratified for disease severity and treatment centre in blocks of four. This, combined with the use of placebo tablets of identical appearance, taste and smell, resulted in blinding of participants, researchers and treating physicians. Six participants randomised to the intervention (four participants) and placebo (two participants) groups withdrew consent before receiving the allocated intervention and were excluded from analysis. Although the investigators recorded outcome data at six-monthly intervals for 24 months, the authors stated that their main analysis would be at 24 months, and reported the primary outcome at only 12 and 24 months and the secondary outcomes only at 24 months. Overall we considered this study to be at low risk of bias.

\section{Effects of interventions}

See: Summary of findings for the main comparison Amantadine versus placebo for fatigue in Guillain-Barré syndrome; Summary of findings 2 Ascorbic acid versus placebo for fatigue in peripheral neuropathy

\section{Amantadine versus placebo in Guillain-Barré syndrome}

Effect estimates, where data were available, were obtained from a single trial, so we downgraded the quality of evidence for all outcomes for this reason (Summary of findings for the main comparison).

\section{Primary outcome}

\section{Fatigue between four and 12 weeks after commencement of intervention}

Garssen 2006 assessed baseline measures at visit 1 and at visit 2, prior to randomisation. In the 74 participants for whom full outcome data were reported, there was evidence of a reduction in fatigue between these baseline visits, which was stated by the authors to approach significance ( $\mathrm{P}=0.05 \mathrm{Wilcoxon}$ signed rank test), although complete group data were not presented. The magnitude of fatigue reduction before the start of any intervention was such that although the median FSS score for the 74 participants was 5.9 at visit 2, seven (9\%) of the participants had an FSS score lower than the inclusion criterion of FSS 5 for severe fatigue.

Thirty-six participants received amantadine followed by placebo and 38 received placebo followed by amantadine. Favourable outcome reporting was available for both phases of each treatment sequence, representing evaluation of the primary outcome six weeks after the commencement of intervention. Results were presented as the mean difference (MD) in reduction in FSS scores between amantadine and placebo, and as an odds ratio (OR) of a favourable outcome (defined as a reduction of more than 1 in FSS score). The overall MD in FSS score between amantadine and placebo phases was -0.45 (95\% CI -0.94 to $0.04 ; t=-1.80 ; \mathrm{df}=73 ; \mathrm{P}=0.076)$. When the participants responding favourably to one treatment only in both the group receiving amantadine followed by placebo (amantadine-placebo group) and those receiving placebo followed by amantadine (placebo-amantadine group) were combined, the number with a more favourable outcome following amantadine was 9 of $25(36 \%)$ participants with an OR of 0.56 (95\% CI 0.22 to $1.35, \mathrm{P}=0.16)$ using the $\mathrm{McNemar}$ test.

\section{Secondary outcomes}

All stated secondary outcomes in Garssen 2006 were only reported at six weeks after commencement of the intervention and therefore not at the stated secondary outcome point of 12 or more weeks 
after commencement of intervention for this review. In addition full data for the study secondary outcomes were not available, as only P values were provided (Garssen 2006). The data indicated that there was no significant improvement in: fatigue impact using the fatigue impact scale (FIS) $(\mathrm{P}=0.77)$; participation using the Rotterdam Handicap Scale (RHS) $(\mathrm{P}=0.14)$ and Euroquol Health Questionnaire (EQHQ) $(\mathrm{P}=0.21)$ at six weeks. The authors reported that quality of life using the SF-36 demonstrated a significant improvement in physical role functioning $(\mathrm{P}=0.008)$ and mental health perception $(\mathrm{P}=0.008)$, although only in the placebo group (Garssen 2006). We contacted the authors for further information about secondary outcomes; the RHS scores for participation at six weeks from the original data were provided by the trial author (Garssen 2006). The data were analysed using a paired two-sample t-test and showed that the MD between the change in participation with placebo versus the change with amantadine between four to 12 weeks after commencement of intervention was 0.31 ( $95 \% \mathrm{CI}-0.09$ to $0.72, \mathrm{P}=0.13$ ) (Table 1$)$. (Summary of findings for the main comparison).

Fatigue after 12 or more weeks

Not reported at this time point.

Activity limitations after 12 or more weeks

Not reported at this time point.

Participation restrictions after 12 or more weeks

Not reported at this time point.

Health-related quality of life (HRQoL) after 12 or more weeks Not reported at this time point.

\section{Adverse events}

Reported in Garssen 2006.

No serious adverse events were reported. However, mild, transient adverse effects were reported in 32 out of 80 (40\%) participants: 22 participants during amantadine treatment and 10 during placebo treatment. Adverse effects included anticholinergic complaints (six participants: three in each treatment group), gastrointestinal complaints (10 participants: seven in placebo group and three in amantadine group), sleep complaints (10 participants: nine in amanta- dine group and one in placebo group) and other less frequent side effects (headache, feelings of nervousness and vivid dreams). No side effects were reported to have affected trial participation.

\section{Ascorbic acid versus placebo in Charcot-Marie-Tooth disease}

\section{Primary outcome}

Fatigue between four and 12 weeks after commencement of intervention

Neither study evaluating ascorbic acid for Charcot-Marie-Tooth disease $1 \mathrm{~A}$ reported change in fatigue within the time scale of the primary outcome for this review (Micallef 2009; Pareyson 2011).

\section{Secondary outcomes}

Data for secondary outcomes were reported at 12 months after commencement of the intervention in Micallef 2009 and at 24 months after commencement of the intervention in Pareyson 2011. Where two different doses of ascorbic acid were used in Micallef 2009, we combined data from both intervention arms, including participants receiving a higher dose (3 g ascorbic acid) and those receiving a lower dose ( $1 \mathrm{~g}$ ascorbic acid) in comparisons for all outcomes.

\section{Fatigue after more than 12 weeks}

Reported in Micallef 2009 and Pareyson 2011.

Both studies assessed fatigue using change in Visual Analogue Scale for fatigue (VAS-F). Fatigue was assessed at 12-month follow-up using a 0 to 100 VAS for fatigue in Micallef 2009 and at 24-month follow-up using a 0 to 10 VAS for fatigue in Pareyson 2011. The pooled estimate of effect of the change in fatigue more than 12 weeks after commencement of the intervention was standardised mean difference (SMD) -0.12 (95\% CI -0.32 to $0.08, \mathrm{P}=0.25$; $\mathrm{N}=404 ; \mathrm{I}^{2}=0 \%$ ) (see Analysis 1.1; Figure 2).

Figure 2. Forest plot of comparison: 2 Ascorbic acid versus placebo, outcome: 2.1 Change in fatigue $>12$ weeks after commencement of intervention at 12 months [VAS 0 - 100).

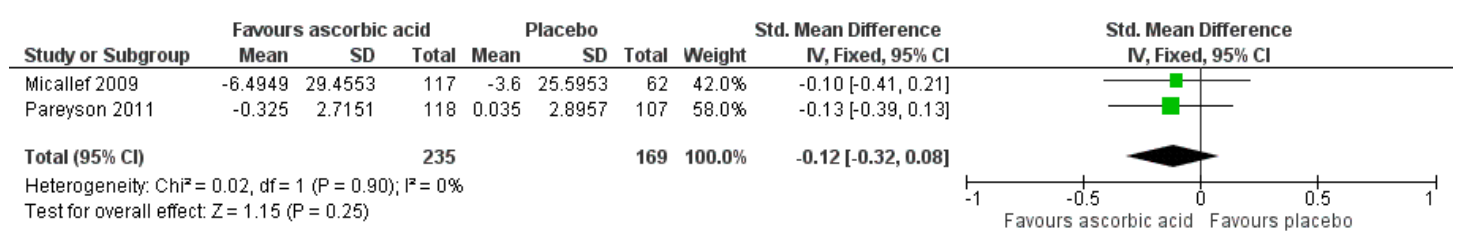

Interventions for fatigue in peripheral neuropathy (Review)

Copyright () 2014 The Cochrane Collaboration. Published by John Wiley \& Sons, Ltd. 


\section{Activity limitations after 12 or more weeks}

Reported in Micallef 2009 and Pareyson 2011. Activity limitation was assessed using the ODSS at 12 months after commencement of intervention in Micallef 2009 and the Overall Neuropathy Limitations Scale (ONLS) 24 months after commencement of intervention in Pareyson 2011. Pooling of data in a meta-analysis was not possible since data for ordinal scale scores were presented as medians plus interquartile ranges (IQRs), and there was no indication of whether the data were skewed. However, the authors reported that there was no significant difference $(P=0.22)$ in median change in activity limitation between placebo and $1 \mathrm{~g}$ or $3 \mathrm{~g}$ doses of ascorbic acid at 12 months in Micallef
2009 , and no significant difference $(P=0.99)$ in median change in activity limitation between placebo and $1.5 \mathrm{~g}$ dose of ascorbic acid in Pareyson 2011.

In addition, further measures of activity limitation were included in both studies. The 10MWT was measured in both Micallef 2009 and Pareyson 2011 (at 12 months and 24 months, respectively) and the pooled estimate of effect for change in time taken to walk 10 metres more than 12 weeks after commencement of the intervention was $\mathrm{MD}-0.39(95 \% \mathrm{CI}-1.04$ to $0.26, \mathrm{P}=0.24 ; \mathrm{N}=$ 406; $\mathrm{I}^{2}=0 \%$ ) (Analysis 1.2; Figure 3). In addition the 9HPT was measured in Pareyson 2011 at 24 months and showed that there was no significant effect of ascorbic acid (MD -0.74, 95\% CI 1.60 to $0.12, \mathrm{P}=0.09 ; \mathrm{N}=224$ ) (Analysis 1.3 ).

Figure 3. Forest plot of comparison: I Ascorbic acid versus placebo, outcome: I.2 Change in $10 \mathrm{~m}$ timed walk > 12 weeks after commencement of the intervention (measured at 12 to 24 months) [seconds].

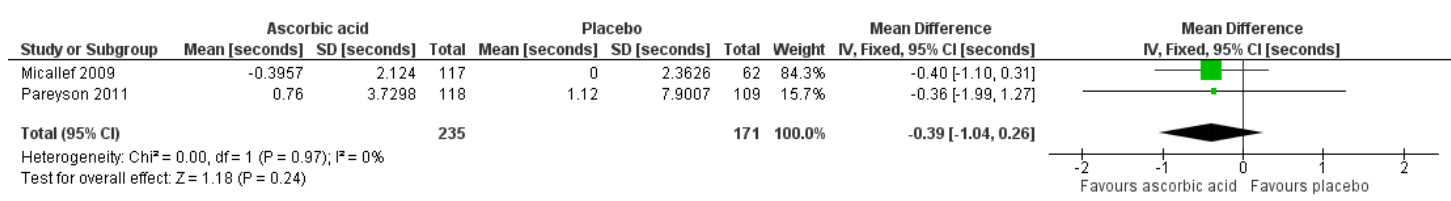

\section{Participation restrictions after 12 or more weeks}

Not reported in Micallef 2009 or Pareyson 2011.

\section{Health-related quality of life (HRQoL) after 12 or more weeks}

Reported as an outcome and assessed using the SF-36 at 12 months after commencement of the intervention in Micallef 2009 and 24 months after commencement of the intervention in Pareyson 2011. We calculated a pooled estimate of the change in physical functioning, as measured by the Physical Component Score (PCS) in Micallef 2009 and the Physical Function Scale (PFS) of the SF36 in Pareyson 2011. Using data from 400 participants, the SMD was 0.08 ( $95 \%$ CI -0.12 to 0.28 ) favouring placebo (see Figure 4 , Analysis 1.4). There was no significant statistical heterogeneity, despite the difference in duration of follow-up $\left(\mathrm{I}^{2}=0 \%, \mathrm{P}=0.67\right)$.

Figure 4. Forest plot of comparison: 2 Ascorbic acid versus placebo, outcome: 2.4 Change in physical function score of SF-36.

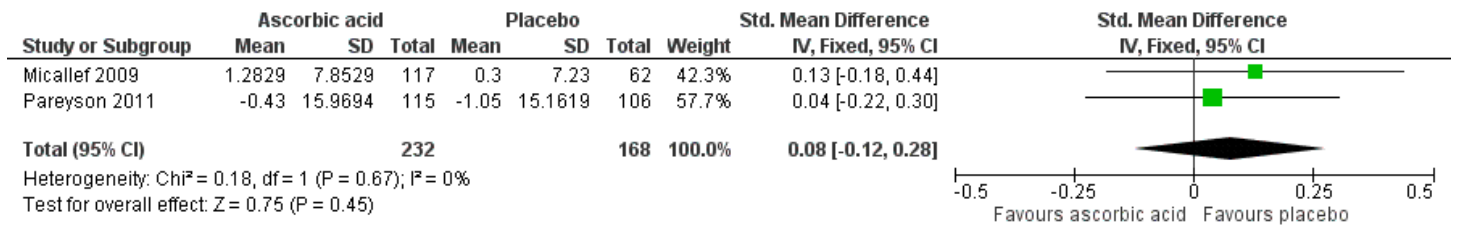


Micallef 2009 reported HRQoL assessed by the Mental Component Score of the SF-36 and for this too there was no significant difference $(P=0.77)$ between either dose of ascorbic acid versus placebo or in a combined analysis, between both doses of ascorbic acid versus placebo, 12 months after the start of treatment (Analysis 1.5).

\section{Adverse events}

Reported in Micallef 2009 and Pareyson 2011.

In Micallef 2009, 896 adverse events were documented in 158 (89\%) participants (55 of 62 participants in the placebo group (89\%); 47 of 56 participants in the $1 \mathrm{~g}$ ascorbic acid group (89\%), and 56 of 61 participants in the $3 \mathrm{~g}$ ascorbic acid group (92\%)), of which only 24 were serious adverse events. Serious adverse events were recorded in 22 participants (eight in the placebo group, seven in the $1 \mathrm{~g}$ ascorbic acid group and seven in the $3 \mathrm{~g}$ ascorbic acid group). Researchers deemed the majority of events (70\%) not to be related to treatment and $208(25 \%)$ to have a possible relation to treatment, of which only 12 (11 listed in the report) were severe: upper abdominal pain (2), dyspepsia (2), headache (1), insomnia (1), muscle spasm (1), musculoskeletal stiffness (1), rash (1), rhinitis (1) and sleep disturbance (1). Six participants (one in the placebo group, four in the $1 \mathrm{~g}$ ascorbic acid group and one in the $3 \mathrm{~g}$ ascorbic acid group) gave adverse events (cystitis, myalgia, depression, colitis and insomnia) as reasons for withdrawal from the study.

In Pareyson 2011, 21 serious adverse events were documented in 20 participants (eight events in seven of 138 participants in the ascorbic acid group and 13 events in 13 of 133 participants in the placebo group). Researchers considered all but one event, where a woman in the placebo group was admitted to hospital due to anaemia, as unrelated to the intervention. Thirteen participants experiencing adverse events were lost to follow-up (six in the placebo group and seven in the ascorbic acid group), and eight participants (six in the placebo group and two in the ascorbic acid group) ceased treatment as a result of a serious adverse event. Five of these eight continued with follow-up and three (two receiving placebo and one receiving ascorbic acid) withdrew from the study. Adverse events in those who discontinued the interventions included gastralgia, abdominal cramps or diarrhoea (9), surgery (4), renal colic (1), pregnancy (3), rectal bleeding (1), saccharine intolerance (1) and gum disease (1). The pooled risk ratio (RR) for serious adverse events in studies of ascorbic acid for CMT1A was 0.70 ( $95 \%$ CI 0.39 to $\left.1.27, \mathrm{P}=0.24 ; \mathrm{N}=450 ; \mathrm{I}^{2}=0 \%\right)$ (see Analysis 1.6, Figure 5), indicating no significant difference in serious adverse events between ascorbic acid and placebo.

Figure 5. Forest plot of comparison: 2 Ascorbic acid versus placebo, outcome: 2.6 Adverse events.

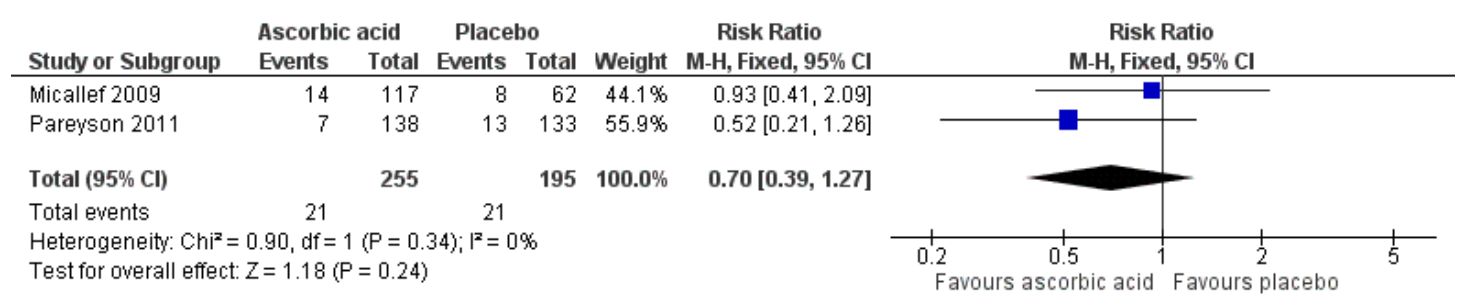

Interventions for fatigue in peripheral neuropathy (Review) 


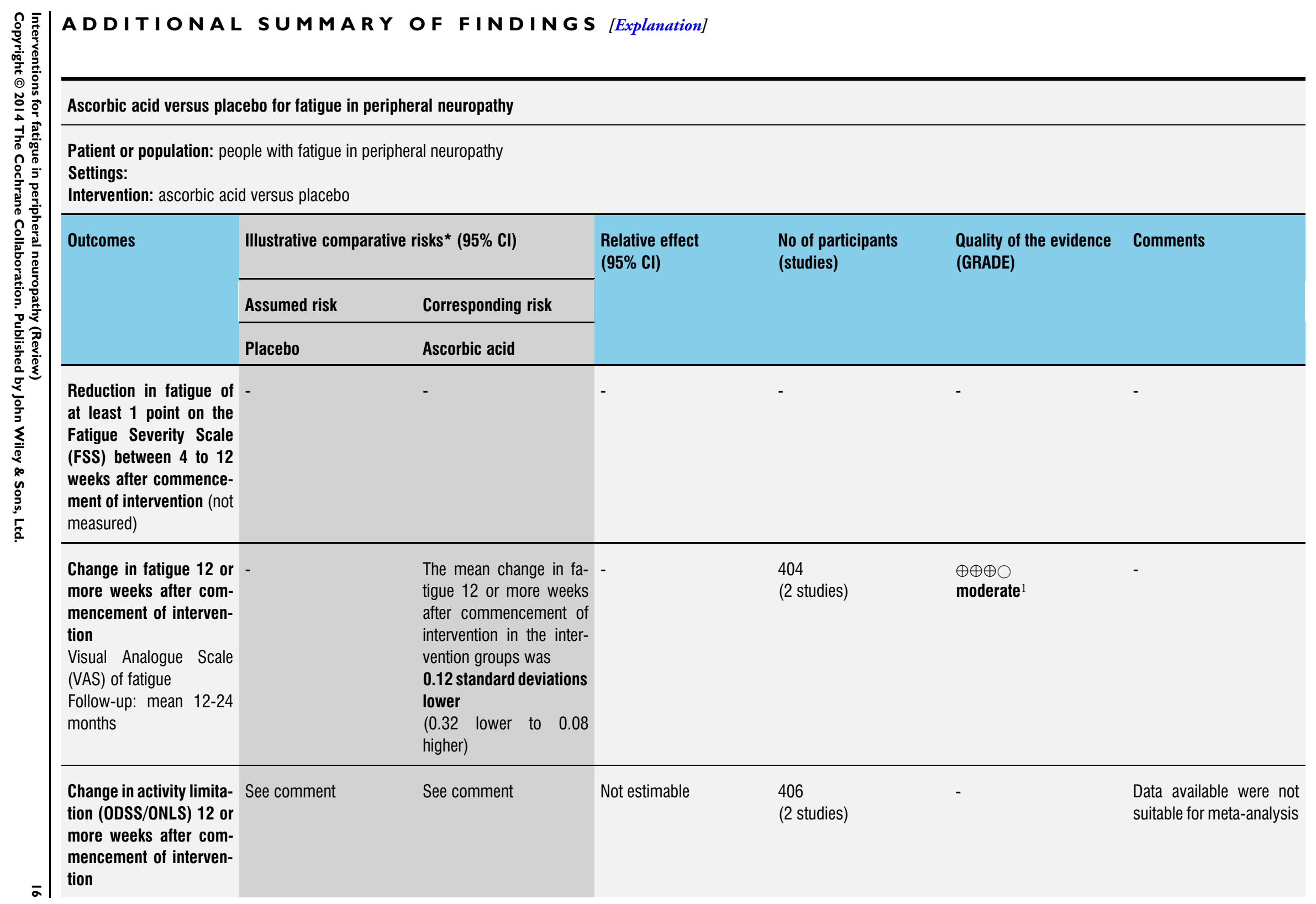




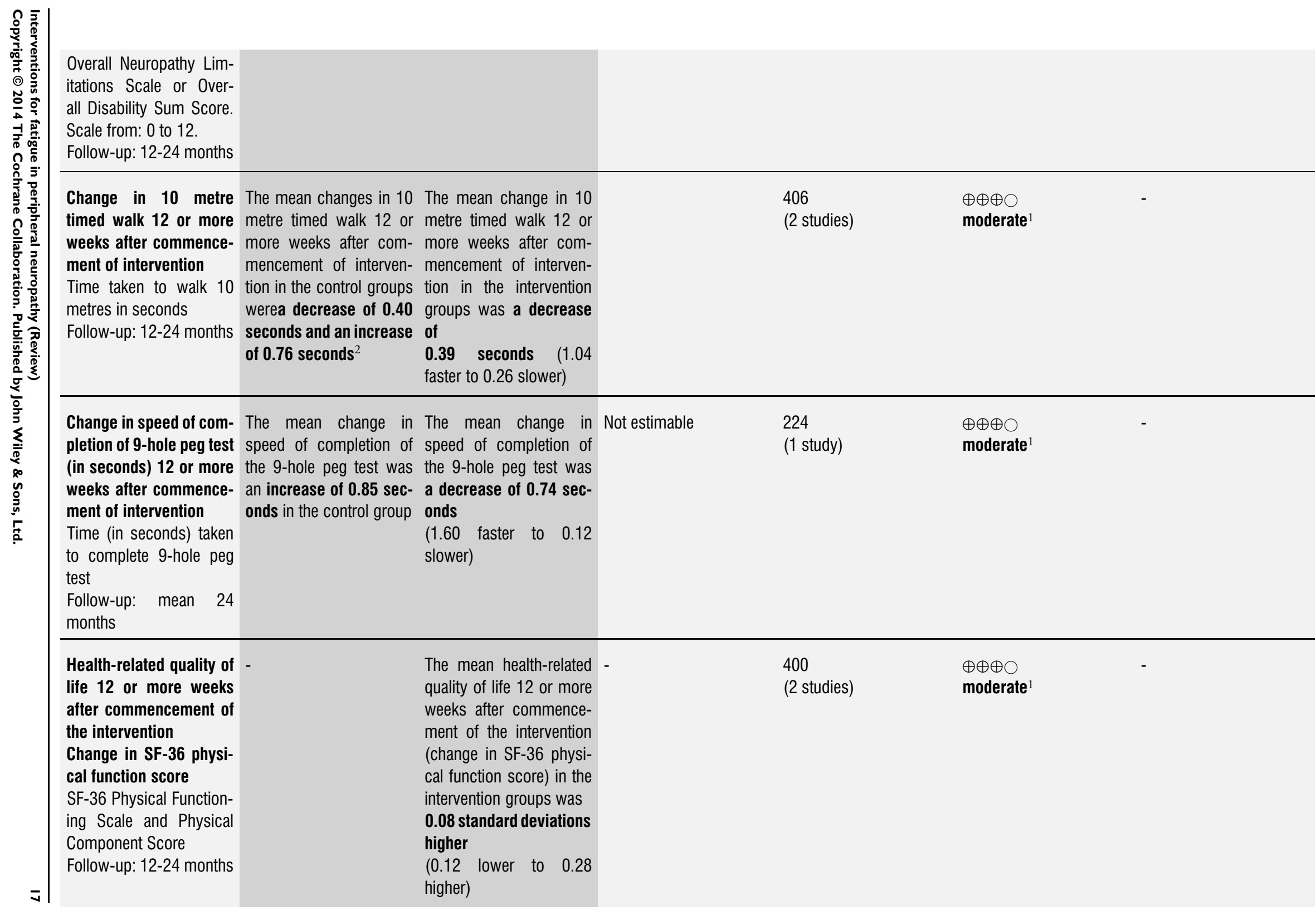




\begin{tabular}{|c|c|c|c|c|c|c|}
\hline $\begin{array}{l}\text { Change in participation } \\
12 \text { or more weeks after } \\
\text { commencement of inter- } \\
\text { vention (not measured) }\end{array}$ & - & - & - & - & - & - \\
\hline $\begin{array}{l}\text { Health-related quality of } \\
\text { life } 12 \text { or more weeks } \\
\text { after commencement of } \\
\text { the intervention Change } \\
\text { in mental function score } \\
\text { of SF-36 } \\
\text { SF-36 Mental Component } \\
\text { Score } \\
\text { Follow-up: mean } 12 \\
\text { months }\end{array}$ & $\begin{array}{l}\text { The mean change in } \\
\text { health-related quality of } \\
\text { life } 12 \text { or more weeks } \\
\text { after commencement of } \\
\text { the intervention (change } \\
\text { in mental function score } \\
\text { of SF-36) in the control } \\
\text { group was } 1.2 \text { points }\end{array}$ & $\begin{array}{l}\text { The mean health-related } \\
\text { quality of life } 12 \text { or more } \\
\text { weeks after commence- } \\
\text { ment of the intervention } \\
\text { (change in mental func- } \\
\text { tion score of SF-36) in the } \\
\text { intervention groups was } \\
\mathbf{0 . 9} \text { higher } \\
\text { (2.65 lower to } 4.45 \\
\text { higher) }\end{array}$ & - & $\begin{array}{l}123 \\
\text { (1 study) }\end{array}$ & $\begin{array}{l}\oplus \oplus \oplus \bigcirc \\
\text { moderate }^{1}\end{array}$ & - \\
\hline $\begin{array}{l}\text { Serious adverse events } \\
\text { Follow-up: } 12 \text { months }\end{array}$ & 108 per 1000 & $\begin{array}{l}76 \text { per } 1000 \\
(42 \text { to } 137)\end{array}$ & $\begin{array}{l}\text { RR } 0.70 \\
\text { (0.39 to } 1.27)\end{array}$ & $\begin{array}{l}450 \\
\text { (2 studies) }\end{array}$ & $\begin{array}{l}\oplus \oplus \oplus \oplus \\
\text { moderate }^{1}\end{array}$ & - \\
\hline
\end{tabular}

*The basis for the assumed risk (e.g. the median control group risk across studies) is provided in footnotes. The corresponding risk (and its $95 \%$ confidence interval) is based on the assumed risk in the comparison group and the relative effect of the intervention (and its $95 \% \mathrm{Cl}$ ).

Cl: confidence interval; RR: risk ratio

\section{GRADE Working Group grades of evidence}

High quality: Further research is very unlikely to change our confidence in the estimate of effect.

Moderate quality: Further research is likely to have an important impact on our confidence in the estimate of effect and may change the estimate.

Low quality: Further research is very likely to have an important impact on our confidence in the estimate of effect and is likely to change the estimate.

Very low quality: We are very uncertain about the estimate.

Only one or two studies included.

${ }^{2}$ Assumed control group risks are the control group values in the two trials. 


\section{DISCUSSION}

\section{Summary of main results}

Our search identified three randomised controlled trials (RCTs) that met the inclusion criteria. The trials evaluated the effect of two different drugs on fatigue in two different populations of people with peripheral neuropathy. Two studies examined the effect of different doses of ascorbic acid in Charcot-Marie-Tooth disease $1 \mathrm{~A}$, and therefore no combined analysis was possible.

The first study (Garssen 2006) was a block-randomised, doubleblind, placebo-controlled, cross-over study of amantadine for severe fatigue in 74 neurologically stable participants at least six months after Guillain-Barré syndrome. We judged the risk of bias of the trial to be low. The study reported a moderate reduction in fatigue severity scale (FSS) score for participants treated with amantadine but the confidence interval was wide and study size relatively small, suggesting that the study may have been underpowered to detect a difference; we therefore graded the quality of the evidence as low. These data indicate that larger studies might improve the power to detect a reduction in risk of fatigue with amantadine. Nevertheless, the mean difference (MD) did not exceed the minimal clinically important difference for change in FSS scores estimated for people with systemic lupus erythematosus (MD 0.6; $95 \%$ CI 0.3 to 0.9 ), indicating that it is likely that there is no effect of amantadine compared with placebo in the treatment of severe fatigue (see Summary of findings for the main comparison). A significant decrease in fatigue was noted between two pre-treatment baseline visits two weeks apart. Since the participants were considered to be neurologically stable, this suggests that increased attention to people with fatigue due to GuillainBarré syndrome may improve symptoms of fatigue.

The two studies evaluating ascorbic acid for Charcot-Marie-Tooth (CMT) disease 1A were block-randomised, double-blind, placebocontrolled trials of different doses of ascorbic acid for the treatment of Charcot-Marie-Tooth disease 1A (Micallef 2009; Pareyson 2011). The risk of bias for Micallef 2009 was low, despite the fact that there was no report of how missing data were dealt with in the intention-to-treat analysis. All other aspects of risk of bias assessment were adequate. The main findings were that whilst ascorbic acid was well-tolerated and safe for adults with Charcot-MarieTooth disease $1 \mathrm{~A}$ over a period of 12 months, there were no significant differences in effect across all outcomes, including fatigue, between placebo, $1 \mathrm{~g}$ or $3 \mathrm{~g}$ of ascorbic acid (see Summary of findings 2). There was a low risk of bias in the remaining study (Pareyson 2011), and the main findings were that ascorbic acid supplementation at a dose of $1.5 \mathrm{~g}$ per day for 24 months was well tolerated but there was no significant effect on neuropathy or secondary outcomes compared with placebo.

\section{Overall completeness and applicability of evidence}

Only three RCTs (Garssen 2006; Micallef 2009; Pareyson 2011) were eligible for inclusion in the review. One was of amantadine for severe fatigue in Guillain-Barré syndrome and the others were of three different doses of ascorbic acid for people with CharcotMarie-Tooth disease 1A. RCTs evaluating the effect of other interventions for fatigue, such as other drugs; pacing and grading of physical activity; general or specific exercise; compensatory strategies such as orthotics; relaxation; counselling; cognitive and educational strategies; and interventions for fatigue that form part of a multidimensional programme, or trials of interventions for other causes of peripheral neuropathy, were not available. None of the included studies considered the cost effectiveness of interventions for fatigue in peripheral neuropathy

\section{Quality of the evidence}

The overall risk of bias in the included trials (Garssen 2006; Micallef 2009; Pareyson 2011) was low.

Garssen 2006 reported a double-blind, placebo-controlled study, where, despite a block randomisation procedure affecting bias in sequence generation and incomplete reporting of secondary outcomes, there was effective allocation concealment and $P$ values for secondary outcomes were available. Reporting of data for fatigue during both phases of the trial indicates that there was no significant carry-over effect. We therefore judged the overall risk of bias to be low.

Micallef 2009 reported a block-randomised, double-blind, placebo-controlled study, where all assessed aspects of risk of bias were adequate except for the lack of reporting of how missing data were dealt with for an intention-to-treat analysis. We therefore judged the overall risk of bias to be low.

Pareyson 2011 reported a block-randomised, double-blind, placebo-controlled study with a low risk of bias overall.

Since only one trial of amantadine for the treatment of fatigue in Guillain-Barré syndrome (Garssen 2006) and two trials of ascorbic acid for treatment of Charcot-Marie-Tooth disease 1A (Micallef 2009; Pareyson 2011) are included in the review, it is not possible to address the review objectives for drug or other interventions. The Garssen 2006 study was relatively small (74 participants) and the results actually suggest that there may be an effect, but the study is under-powered. We downgraded the evidence from this study to low because of its imprecision (Summary of findings for the main comparison). Larger studies including those with different doses and frequency of administration of amantadine are desirable before a definite conclusion about the effect of amantadine to treat fatigue in peripheral neuropathy and in particular in GuillainBarré syndrome can be given.

The studies of ascorbic acid for Charcot-Marie-Tooth disease $1 \mathrm{~A}$ were larger, and evaluated the effect of three different doses of ascorbic acid in Charcot-Marie-Tooth disease 1A (Micallef 2009; Pareyson 2011). The lack of reporting of how missing data were dealt with in Micallef 2009 means that it is difficult to assess 
whether the risk of bias is likely to have favoured the control or ascorbic acid treatment groups in this study. Nevertheless, the low risk of bias associated with the final study (Pareyson 2011) and the fact that it has similar findings to Micallef 2009 meant that we did not downgrade the evidence because of trial design or conduct, but did downgrade it because of the lack of reporting of how missing data was dealt with in Micallef 2009. This means that there is moderate-quality evidence suggesting that ascorbic acid has no benefit in the treatment of fatigue in CMT (See Summary of findings 2).

The primary outcome of fatigue was evaluated using the FSS or VAS for fatigue in the included studies. The FSS is based on classical test theory (CTT), where scales may include items not relevant for particular clinical populations, and scale sum scores assume equal weighting of items where this has not necessarily been demonstrated. This potentially introduces bias into the assessment of the underlying outcome of interest. However, evidence in the current review was not downgraded due to directness based on outcomes used, since the effect of indirectness is not currently known. Nevertheless, clinicians and researchers are moving towards linearly weighted scales based on modern scientific methods such as Rasch models or item response theory (IRT) for evaluation of outcomes in clinical populations. The FSS has recently been fully evaluated and modified using the Rasch unidimensional measurement model (RUMM2020) and is recommended for use in immune-mediated neuropathy (van Nes 2009). Its relevance for other peripheral neuropathies remains to be evaluated.

\section{Potential biases in the review process}

Two review authors were also investigators in an included trial (Garssen 2006), but neither was involved in assessing the risk of bias in this study.

We contacted study authors where there were missing data, and these was provided by Garssen 2006 for one secondary outcome. We also contacted authors of published abstracts with limited reporting of data for further information, but they either did not reply or declined to, stating their intention to publish a full report of the study in the future as a reason.

This systematic review used an adequate search strategy to avoid missing any RCTs on treatments for fatigue in peripheral neuropathy. There were no language restrictions in our searches, and whilst a limitation of the review is that we did not initially plan in our protocol to search clinical trials registers, this additional search was subsequently conducted; this difference between the protocol and review is flagged up below.

The criteria for types of participants for including studies accepted the diagnosis of peripheral neuropathy offered by the authors, provided that it stipulated the presence of clinical impairment characteristic of peripheral neuropathy. We considered only sensory, motor or combined sensory and motor peripheral neuropathies, and excluded studies of participants with focal entrapment neu- ropathies with pain as the primary presenting feature, and with poliomyelitis. There is therefore a small possibility that misdiagnosis of participants may have affected study inclusion, and that studies with mixed populations of participants that include both sensory, motor and combined sensory motor neuropathies as well as painful entrapment neuropathies or poliomyelitis were excluded. This could be a potential source of selection bias in the review.

\section{Agreements and disagreements with other studies or reviews}

There are currently no other systematic reviews of interventions for fatigue in peripheral neuropathy available, despite many treatments for fatigue including: drugs, pacing and grading of physical activity, general or specific exercise, compensatory strategies such as orthotics, relaxation, counselling, cognitive and educational strategies, either alone or as part of a multidimensional programme.

\section{Systematic reviews of interventions for fatigue in other conditions}

In the absence of evidence from reviews or high-quality RCTs in peripheral neuropathy it may be helpful to consider the effect of interventions for fatigue in other conditions, including chronic fatigue syndrome (CFS), fibromyalgia, multiple sclerosis and cancer-related fatigue. The high incidence of anxiety and depression in functional somatic syndromes such as fibromyalgia and CFS (Henningsen 2003) and the specific pathophysiological features of multiple sclerosis and cancer-related fatigue mean that recommendations from systematic reviews should be considered with caution. In all cases we included only evidence from Cochrane systematic reviews.

\section{Drugs for fatigue}

The evidence from Cochrane systematic reviews of drugs in the treatment of fatigue in other conditions was of varying quality. A systematic review of serotonin and noradrenaline reuptake inhibitors (SNRIs) for fibromyalgia indicated that they only provide a small improvement in fatigue ( $1.7 \%$ improvement) over placebo (Hauser 2013). In reviews of amantadine or carnitine for fatigue in multiple sclerosis, the poor quality of the available RCTs meant that no conclusion regarding their efficacy could be drawn (Pucci 2009; Tejani 2012). Finally, whilst the updated systematic review of drug therapy for the management of cancer-related fatigue provides evidence that psychostimulant trials may give a clinically meaningful improvement in cancer-related fatigue, new safety data indicate that the drugs are associated with increased adverse outcomes and they can no longer be recommended in the treatment of cancer-related fatigue (Minton 2010).

Non-drug interventions for fatigue 
We reviewed the evidence from recent Cochrane systematic reviews of non-drug interventions for fatigue in other conditions, which suggests that exercise (Edmonds 2004) and cognitive behavioural therapy (CBT) (Price 2008) for fatigue in CFS are both better than usual care, with the evidence for CBT being more extensive and robust than for exercise. In a review of exercise for treating fibromyalgia syndrome, there is very limited evidence that aerobic-only exercise is likely to have no effect on fatigue in individuals with fibromyalgia (Busch 2007). A systematic review of cognitive behavioural therapies for fibromyalgia concludes that there was only a $5.8 \%$ (95\% CI 0.05 to 11.3 ) effect on fatigue (Bernardy 2013). A systematic review of exercise for management of cancer-related fatigue concluded that aerobic exercise is beneficial (Cramp 2012).

\section{Evidence from individual studies of interventions for fatigue in neuropathy}

One article describing an uncontrolled case series of people with Charcot-Marie-Tooth disease $1 \mathrm{~A}$ treated with modafinil for fatigue reported that all four participants had less fatigue within at least 10 days of commencing modafinil treatment (Carter 2006). The case study design means that this report has substantial risk of bias but may suggest that modafinil is a potentially useful drug for fatigue in people with Charcot-Marie-Tooth disease 1A, and merits welldesigned trials.

The wide variety of causes and consequences in peripheral neuropathy, combined with a relatively low prevalence of individual conditions means that controlled trials of non-drug interventions have been limited. In addition, despite the substantial prevalence of fatigue in people with peripheral neuropathy (Merkies 1999), subjective fatigue is not routinely evaluated in RCTs and other study designs of such interventions. However, one cohort study (Garssen 2004) and one case-control study (Graham 2007) of exercise for people with Guillain-Barré syndrome and chronic inflammatory demyelinating polyradiculoneuropathy (CIDP) reported significant reductions in fatigue after 12 weeks of either supervised aerobic cycling (Garssen 2004) or unsupervised community-based exercise (Graham 2007). Whilst these studies are subject to very high risks of bias due to their design, they may suggest that RCTs of exercise for people with fatigue due to peripheral neuropathy should be conducted.

\section{AUTHORS' CONCLUSIONS}

\section{Implications for practice}

The evidence from randomised controlled trials of the efficacy of interventions for fatigue in peripheral neuropathy is limited. One small study comparing amantadine with placebo for fatigue in people with Guillain-Barré syndrome was not sufficiently powered to determine the effects on fatigue in this population. There was moderate quality evidence that the effects of ascorbic acid on fatigue in people with Charcot-Marie-Tooth disease 1A are small. Information about adverse effects was limited, although both treatments appeared to be well tolerated in these conditions.

There was no evidence available from randomised controlled trials to evaluate the effect of other interventions for fatigue in either Guillain-Barré syndrome, Charcot-Marie-Tooth disease $1 \mathrm{~A}$ or other causes of peripheral neuropathy.

\section{Implications for research}

The dearth of evidence from high-quality randomised controlled trials on the effects of interventions for fatigue in peripheral neuropathy indicates that treatments for this condition warrant further research. Trials in relevant patient populations should have adequate sample size, appropriate randomised controlled designs and clinically relevant standardised and responsive measures of fatigue as an outcome.

\section{ACK NOW LEDGEMENTS}

The staff of the Cochrane Neuromuscular Disease Group (CNMDG).

The Trials Search Co-ordinator of the CNMDG developed search strategies in collaboration with the review authors and provided the literature searches.

Editorial support from the CNMDG is supported by funding from the MRC Centre for Neuromuscular Diseases. 


\section{R E F E R E N C E S}

\section{References to studies included in this review}

\section{Garssen 2006 \{published data only\}}

Garssen MPJ, Schmitz PIM, Merkies ISJ, Jacobs BC, van der Meché FGA, van Doorn PA. Amantadine for treatment of fatigue in Guillain-Barré syndrome: a randomised, double blind, placebo controlled, crossover trial. Journal of Neurology, Neurosurgery and Psychiatry 2006;77(1):61-5. [PUBMED: 16361594]

Micallef 2009 \{published data only\} Micallef J, Attarian S, Dubourg O, Gonnaud P-M, Hogrel $\mathrm{J}-\mathrm{Y}$, Stojkovic T, et al.Effect of ascorbic acid in patients with Charcot-Marie-Tooth disease type 1A: a multicentre, randomised, double-blind, placebo-controlled trial. Lancet Neurology 2009;8(12):1103-10. [PUBMED: 19818690]

Pareyson 2011 \{published data only\} Pareyson D, Reilly MM, Schenone A, Fabrizi GM, Cavallaro T, Santoro L, et al.Ascorbic acid in Charcot-Marie-Tooth disease type 1A (CMT-TRIAAL and CMT-TRAUK): a double-blind randomised trial. Lancet Neurology 2011;10 (4):320-8. [PUBMED: 21393063]

\section{References to studies excluded from this review}

\section{Burns 2009 \{published data only\}}

Burns J, Ouvrier RA, Yiu EM, Joseph PD, Kornberg AJ, Fahey MC, et al.Ascorbic acid for Charcot-Marie-Tooth disease type $1 \mathrm{~A}$ in children: a randomised, double-blind, placebo-controlled safety and efficacy trial. Lancet Neurology 2009;8(6):537-44.

Carter 2006 \{published data only\} Carter GT, Han JJ, Mayadev A, Weiss MD. Modafinil reduces fatigue in Charcot-Marie-Tooth disease type 1A: a case series. American Journal of Hospice and Palliative Care 2006;23(5):412-6.

Enderlin 2008 \{published data only\} Enderlin CA. Peripheral neuropathy, sleep and fatigue related to cancer and chemotherapy: preliminary findings. Southern Online Journal of Nursing Research 2008;8(2):2p.

NCT00484510 \{published and unpublished data\} NCT00484510. A randomized, placebo-controlled, double masked 120 subject "futility design" clinical trial of ascorbic acid treatment of Charcot Marie Tooth disease type 1A. clinicaltrials.gov/ct2/show/NCT00484510 (accessed 21 January 2013).

Verhamme 2009 \{published data only\} Verhamme C, de Haan RJ, Vermeulen M, Baas F, de Visser $M$, van Schaik IN. Oral high dose ascorbic acid treatment for one year in young CMT1A patients: a randomised, double-blind, placebo-controlled phase 11 trial. $B M C$ Medicine 2009;7(1):70-79.

\section{References to ongoing studies}

Attarian 2013 \{published data only\}

Attarian S, Dubourg O, Funalot B, Gonnaud P-M, Lacour A, Magy L, et al.A phase II randomized, placebo-controlled multicenter clinical trial of three doses of PXT3003 in 80 adult patients with CMT1A treated for 1 year. Journal of the Peripheral Nervous System 2013;18(s2):S7-S8.

NCT00541164 \{published data only\} NCT00541164. Effects of coenzyme Q10 on CharcotMarie-Tooth disease. //clinicaltrials.gov/ct2/show/ NCT00541164 (accessed 12 June 2014).

NCT02121678 \{published data only\} NCT02121678. Effect of resistance and aerobic exercise in CIDP or MMN. www.clinicaltrials.gov/ct2/show/ NCT02121678 (accessed 12 June 2014).

Ramdharry 2011 \{published data only\} Ramdharry GM, Pollard AJ, Anderson CA, Laurá M, Murphy SM, Hutton EJ, et al.Strengthening hip flexors to improve walking distance in people with Charcot-MarieTooth disease. Journal of the Peripheral Nervous System. 2011; Vol. 16 (Suppl 3):S115-6.

\section{Additional references}

Bernardy 2013

Bernardy K, Klose P, Busch AJ, Choy EHS, Häuser W. Cognitive behavioural therapies for fibromyalgia. Cochrane Database of Systematic Reviews 2013, Issue 9. [DOI: 10.1002/14651858.CD009796.pub2]

Bigland-Ritchie 1978 Bigland-Ritchie B, Jones DA, Hosking GP, Edwards RH. Central and peripheral fatigue in sustained maximum voluntary contractions of human quadriceps muscle. Clinical Science and Molecular Medicine 1978;54(6): 609-14.

Bleijenberg 2003

Bleijenberg G. Chronic fatigue and chronic fatigue syndrome in the general population. Health and Quality of Life Outcomes 2003;1:52.

Busch 2007

Busch AJ, Barber KA, Overend TJ, Peloso PMJ, Schachter CL. Exercise for treating fibromyalgia syndrome.. Cochrane Database of Systematic Reviews 2007, Issue 4. [DOI: 10.1002/14651858.CD003786.pub2]

\section{Cappelen-Smith 2000}

Cappelen-Smith C, Kuwabara S, Lin CS, Mogyoros I, Burke D. Activity-dependent hyperpolarization and conduction block in chronic inflammatory demyelinating polyneuropathy. Annals of Neurology 2000;48(6):826-32.

\section{Chalder 1993}

Chalder T, Berelowitz G, Pawlikowska T, Watts L, Wessely S, Wright D, et al.Development of a fatigue scale. Journal of Psychosomatic Research 1993;37(2):147-53. 


\section{Cohen 1989}

Cohen RA, Fisher M. Amantadine treatment of fatigue associated with multiple sclerosis. Archives of Neurology 1989;46(6):676-80.

Cramp 2012

Cramp F, Byron-Daniel J. Exercise for the management of cancer-related fatigue in adults. Cochrane Database of Systematic Reviews 2012, Issue 11. [DOI: 10.1002/ 14651858.CD006145.pub3]

\section{DerSimonian 1986}

DerSimonian R, Laird N. Meta-analysis in clinical trials. Controlled Clinical Trials 1986;7:177-88.

\section{Edmonds 2004}

Edmonds M, McGuire H, Price JR. Exercise therapy for chronic fatigue syndrome. Cochrane Database of Systematic Reviews 2004, Issue 3. [DOI: 10.1002/ 14651858.CD003200.pub2]

\section{Elbourne 2002}

Elbourne DR, Altman DG, Higgins JPT, Curtin F, Worthington HV, Vail A. Meta-analyses involving crossover trials: methodological issues.. International Journal of Epidemiology 2002;31(1):140-9.

\section{Fisk 1994}

Fisk JD, Ritvo PG, Ross L, Haase DA, Marrie TJ, Schlech WF. Measuring the functional impact of fatigue: initial validation of the fatigue impact scale. Clinical Infectious Diseases 1994;18(Suppl 1):S79-83.

Fisk 2002

Fisk JD, Doble SE. Construction and validation of a fatigue impact scale for daily administration (D-FIS). Quality of Life Research 2002;11(3):263-72.

\section{Gandevia 2001}

Gandevia SC. Spinal and supraspinal factors in human muscle fatigue. Physiological Reviews 2001;81(4):1725-89.

\section{Garssen 2004}

Garssen MP, Bussmann JB, Schmitz PI, Zandbergen A, Welter TG, Merkies IS, et al.Physical training and fatigue, fitness, and quality of life in Guillain-Barré syndrome and CIDP. Neurology 2004;63(12):2393-5.

\section{Garssen 2007}

Garssen MP, Schillings ML, van Doorn PA, van Engelen BG, Zwarts MJ. Contribution of central and peripheral factors to residual fatigue in Guillain-Barré syndrome. Muscle \& Nerve 2007;36(1):93-9.

GRADEpro 2008

Jan Brozek, Andrew Oxman, Holger Schünemann. GRADEpro. 3.2 for Windows. Jan Brozek, Andrew Oxman, Holger Schünemann, 2008.

\section{Graham 2007}

Graham RC, Hughes RAC, White CM. A prospective study of physiotherapist prescribed community based exercise in inflammatory peripheral neuropathy. Journal of Neurology 2007;254(2):228-35.

\section{Hauser 2013}

Häuser W, Urrútia G, Tort $S$, Üçeyler N, Walitt B. Serotonin and noradrenaline reuptake inhibitors (SNRIs) for fibromyalgia syndrome. Cochrane Database of Systematic Reviews 2013, Issue 1. [DOI: 10.1002/ 14651858.CD010292]

Henningsen 2003

Henningsen P, Zimmermann T, Sattel H. Medically unexplained physical symptoms, anxiety, and depression: a meta-analytic review. Psychosomatic Medicine 2003;65(4): 528-33.

\section{Higgins 2003}

Higgins JPT, Thompson SG, Deeks JJ, Altman DG. Measuring inconsistency in meta-analyses. BMJ 2003;327 (7414):557-60.

\section{Higgins 2011a}

Higgins JPT, Green S (editors). Cochrane Handbook for Systematic Reviews of Interventions Version 5.1.0 [updated March 2011]. The Cochrane Collaboration, 2011. Available from www.cochrane-handbook.org.

\section{Higgins 2011b}

Higgins JPT, Deeks JJ (editors). Chapter 7: Selecting studies and collecting data. In: Higgins JPT, Green S (editors). Cochrane Handbook for Systematic Reviews of Interventions Version 5.1.0 (updated March 2011). The Cochrane Collaboration, 2011. Available from www.cochrane-handbook.org.

\section{Kaji 2000}

Kaji R, Bostock H, Kohara N, Murase N, Kimura J, Shibasaki H. Activity-dependent conduction block in multifocal motor neuropathy. Brain 2000;123(Pt 8): 1602-11.

\section{Karlsen 1999}

Karlsen K, Larsen JP, Tandberg E, Jorgensen K. Fatigue in patients with Parkinson's disease. Movement Disorders 1999; 14(2):237-41.

\section{Kent-Braun 1993}

Kent-Braun JA, Sharma KR, Weiner MW, Massie B, Miller RG. Central basis of muscle fatigue in chronic fatigue syndrome. Neurology 1993;43(1):125-31.

\section{Kleyweg 1991}

Kleyweg RP, van der Meché FGA, Schmitz PIM. Interobserver agreement in the assessment of muscle strength and functional abilities in Guillain-Barre syndrome. Muscle \& Nerve 1991;14(11):1103-9.

\section{Krupp 1989}

Krupp LB, LaRocca NG, Muir-Nash J, Steinberg AD. The Fatigue Severity Scale. Application to patients with multiple sclerosis and systemic lupus erythematosus. Archives of Neurology 1989;46(10):1121-3.

\section{Krupp 2003}

Krupp LB. Fatigue in multiple sclerosis: definition, pathophysiology and treatment. CNS Drugs 2003;17(4): 225-34. 
Lee 1991

Lee KA, Hicks G, Nino-Murcia G. Validity and reliability of a scale to assess fatigue. Psychiatry Research 1991;36(3): 291-8.

Lennon 1993

Lennon SM, Koblar S, Hughes RAC, Goeller J, Riser AC. Reasons for persistent disability in Guillain-Barré syndrome. Clinical Rehabilitation 1993;7(1):1-8.

\section{Martinez-Figuerora 1977}

Martinez-Figueroa A, Hansen S, Ballantyne JP. A quantitative electrophysiological study of acute idiopathic polyneuritis. Journal of Neurology, Neurosurgery and Psychiatry 1977;40(2):156-61.

\section{Martyn 1998}

Martyn C, Hughes RAC. Peripheral neuropathies. The Epidemiology of Neurological Disorders. 1st Edition. London: BMJ, 1998.

\section{Merkies 1999}

Merkies IS, Schmitz PI, Samijn JP, van der Meché FG, van Doorn PA. Fatigue in immune-mediated polyneuropathies. European Inflammatory Neuropathy Cause and Treatment (INCAT) Group. Neurology 1999;53(8):1648-54.

\section{Minton 2010}

Minton O, Richardson A, Sharpe M, Hotopf M, Stone P. Drug therapy for the management of cancer-related fatigue. Cochrane Database of Systematic Reviews 2010, Issue 7. [DOI: 10.1002/14651858.CD006704.pub3]

\section{Moss-Morris 2005}

Moss-Morris R, Sharon C, Tobin R, Baldi JC. A randomized controlled graded exercise trial for chronic fatigue syndrome: outcomes and mechanisms of change. Journal of Health Psychology 2005;10(2):245-9.

\section{Pfeiffer 2001}

Pfeiffer G, Wicklein EM, Ratusinski T, Schmitt L, Kunze K. Disability and quality of life in Charcot-Marie-Tooth disease type 1. Journal of Neurology, Neurosurgery and Psychiatry 2001;70(4):548-50.

\section{Piper 1998}

Piper BF, Dibble SL, Dodd MJ, Weiss MC, Slaughter RE, Paul SM. The revised Piper Fatigue Scale: psychometric evaluation in women with breast cancer. Oncology Nursing Forum 1998;25(4):677-84.

\section{Price 2008}

Price JR, Mitchell E, Tidy E, Hunot V. Cognitive behaviour therapy for chronic fatigue syndrome in adults. Cochrane Database of Systematic Reviews 2008, Issue 3. [DOI: 10.1002/14651858.CD001027.pub2]

\section{Pucci 2009}

Pucci E, Brañas P, D’Amico R, Giuliani G, Solari A, Taus C. Amantadine for fatigue in multiple sclerosis. Cochrane Database of Systematic Reviews 2009, Issue 1. [DOI: 10.1002/14651858.CD002818.pub2]

\section{Rosenberg 1988}

Rosenberg GA, Appenzeller O. Amantadine, fatigue, and multiple sclerosis. Archives of Neurology 1988;45(10): 1104-6.

\section{Sanders 1996}

Sanders DB, Stalberg EV, Nandedkar SD. Analysis of the electromyographic interference pattern. Journal of Clinical Neurophysiology 1996;13(5):385-400.

\section{Schillings 2003}

Schillings ML, Hoefsloot W, Stegeman DF, Zwarts MJ. Relative contributions of central and peripheral factors to fatigue during a maximal sustained effort. European Journal of Applied Physiology 2003;90(5-6):562-8.

\section{Schünemann 2011a}

Schünemann HJ, Oxman AD, Higgins JPT, Vist GE, Glasziou P, Guyatt GH. Chapter 11: Presenting results and 'Summary of findings' tables. In: Higgins JPT, Green $S$ (editors), Cochrane Handbook for Systematic Reviews of Interventions Version 5.1.0 (updated March 2011). The Cochrane Collaboration, 2011. Available from www.cochrane-handbook.org.

\section{Schünemann 2011b}

Schünemann HJ, Oxman AD, Vist GE, Higgins JPT, Deeks JJ, Glasziou P, et al.Chapter 12: Interpreting results and drawing conclusions.. In: Higgins JPT, Green $S$ (editors), Cochrane Handbook for Systematic Reviews of Interventions Version 5.1.0 (updated March 2011). The Cochrane Collaboration, 2011. Available from www.cochrane-handbook.org.

\section{Tamura 2007}

Tamura N, Kuwabara S, Misawa S, Kanai K, Nakata M, Sawai $S$, et al.Time course of axonal regeneration in acute motor axonal neuropathy. Muscle \& Nerve 2007;35(6): $793-5$.

\section{Tejani 2012}

Tejani AM, Wasdell M, Spiwak R, Rowell G, Nathwani $\mathrm{S}$. Carnitine for fatigue in multiple sclerosis. Cochrane Database of Systematic Reviews 2012, Issue 5. [DOI: 10.1002/14651858.CD007280.pub3]

\section{van Nes 2009}

van Nes SI, Vanhoutte EK, Faber CG, Garssen M, van Doorn PA, Merkies IS, PeriNomS Study Group. Improving fatigue assessment in immune-mediated neuropathies: the modified Rasch-built Fatigue Severity Scale. Journal of the Peripheral Nervous System 2009;14(4):268-78.

\section{References to other published versions of this review}

\author{
White 2009 \\ White CM, van Doorn PA, Garssen MPJ, Stockley RC. \\ Interventions for fatigue in peripheral neuropathy. Cochrane \\ Database of Systematic Reviews 2009, Issue 4. [DOI: \\ 10.1002/14651858.CD008146] \\ * Indicates the major publication for the study
}




\section{CHARACTERISTICS OF STUDIES}

\section{Characteristics of included studies [ordered by study ID]}

\section{Garssen 2006}

\begin{tabular}{|c|c|}
\hline Methods & $\begin{array}{l}\text { Randomised, double-blind, placebo-controlled, cross-over trial } \\
\text { Duration } 18 \text { weeks: } \\
\text { - } 2 \text { weeks pre-treatment period } \\
\text { - } 6 \text { weeks first intervention period } \\
\text { - } 2 \text { weeks washout } \\
\text { - } 6 \text { weeks second intervention period } \\
\text { - } 2 \text { weeks washout } \\
\text { Block randomisation in blocks of } 6\end{array}$ \\
\hline Participants & $\begin{array}{l}\text { Identified from Dutch Guillain-Barré syndrome databank or the Dutch Neuromuscular } \\
\text { Disorders Patients Association (Vereniging Spierziekten Nederland) } \\
80 \text { ( } 40 \text { female and } 40 \text { male) neurologically stable participants with GBS (no apparent } \\
\text { change in GBS disability score within } 3 \text { months of the start of the study) with severe } \\
\text { fatigue (mean FSS score of } \geq 5 \text { ) who were over } 18 \text { years old, with a GBS disability score } \\
<3 \text { (able to walk at least } 10 \text { metres with or without aid) } \\
\text { Exclusion criteria: presence of severe fatigue prior to onset of GBS, comorbidity with } \\
\text { conditions that might cause fatigue, receiving medication that may induce fatigue, score } \\
\text { of }>10 \text { on the depression subscale of the HADS, contraindications for treatment with } \\
\text { amantadine including pregnancy and breastfeeding, renal dysfunction, and allergy to } \\
\text { amantadine }\end{array}$ \\
\hline
\end{tabular}

Interventions

Amantadine $100 \mathrm{mg}$ once daily for 1 week then twice daily for 5 weeks ( $\mathrm{n}=40$ allocated, 36 in analysis) or placebo ( $\mathrm{n}=40$ allocated, 38 in analysis), followed after washout by the opposite intervention

\begin{tabular}{|l|l}
\hline Outcomes & 1. Reduction in severe fatigue by at least 1 point on the FSS \\
2. Impact of fatigue - FIS \\
3. Mood - HADS \\
4. Participation/handicap - RHS \\
5. Quality of life - SF-36 and EQHQ
\end{tabular}

Funding

This study was supported by a grant from the Dutch Organization for Scientific Research, NWO (grant no. 940-38-009)

\begin{tabular}{l|l}
\hline Declarations of interest & None stated \\
\hline Notes & $\begin{array}{l}7 \text { people were excluded prior to randomisation for insufficient fatigue }(<5 \text { on FSS) } \\
\text { Ethical approval was gained in May } 2000 \text { but no information on the duration of the } \\
\text { study is reported }\end{array}$
\end{tabular}

\section{Risk of bias}




\section{Garssen 2006 (Continued)}

\author{
Random sequence generation (selection Low risk \\ bias)
}

Allocation concealment (selection bias) Low risk

Allocation sequence generated by block randomisation (block size of 6 )

Allocation sequence list sent to pharmacy department and consecutive people at outpatient department assigned a number from 1 to 80 in sequence of entering the study

Blinding (performance bias and detection Low risk Placebo-controlled trial

bias)

All outcomes

Incomplete outcome data (attrition bias) Low risk All outcomes

Low risk

All outcomes

\begin{tabular}{|c|c|c|}
\hline $\begin{array}{l}\text { Random sequence generation (selection } \\
\text { bias) }\end{array}$ & Low risk & $\begin{array}{l}\text { Allocation sequence generated by block } \\
\text { randomisation (block size of } 6 \text { ) }\end{array}$ \\
\hline Allocation concealment (selection bias) & Low risk & $\begin{array}{l}\text { Allocation sequence list sent to pharmacy } \\
\text { department and consecutive people at out- } \\
\text { patient department assigned a number } \\
\text { from } 1 \text { to } 80 \text { in sequence of entering the } \\
\text { study }\end{array}$ \\
\hline $\begin{array}{l}\text { Blinding (performance bias and detection } \\
\text { bias) } \\
\text { All outcomes }\end{array}$ & Low risk & Placebo-controlled trial \\
\hline $\begin{array}{l}\text { Incomplete outcome data (attrition bias) } \\
\text { All outcomes }\end{array}$ & Low risk & $\begin{array}{l}\text { Analysis based on } 74 \text { participants, as } 6 \\
\text { withdrawn: } 3 \text { from first intervention period } \\
\text { ( } 1 \text { from the placebo group and } 2 \text { from the } \\
\text { amantadine group) and a further } 3 \text { partic- } \\
\text { ipants withdrawn due to inadequate com- } \\
\text { pletion of FSS }\end{array}$ \\
\hline Selective reporting (reporting bias) & High risk & $\begin{array}{l}\text { Only P values reported for } 4 \text { secondary out- } \\
\text { comes: fatigue impact, mood, participation } \\
\text { limitation, and quality of life }\end{array}$ \\
\hline Other bias & Low risk & $\begin{array}{l}\text { Washout period similar to studies of aman- } \\
\text { tadine in other populations. Carry-over ef- } \\
\text { fect of } 2 \text {-week washout period tested by au- } \\
\text { thors and no significant effect reported }\end{array}$ \\
\hline
\end{tabular}

Placebo-controlled trial

\section{Micallef 2009}

Methods

Participants
Block-randomised, double-blind, placebo-controlled, multicentre trial

Duration: 12 months

Participants were recruited from 3 hospital sites in France

195 patients were initially screened and 179 (110 women and 69 men) with a clinical diagnosis of CMT1A confirmed by genotyping with duplication in $17 \mathrm{p} 11.2$ were subsequently randomised prior to intervention

Participants were aged between 18 and 70 years of age and had to have at least one motor symptom or sign (gait disorder, distal amyotrophy, foot deformation or muscle weakness). People with any cause of neuropathy other than CMT1A and other medical conditions: kidney stones, hypersensitivity or intolerance to ascorbic acid or lactose, uncorrected oxalosis, cardiovascular disease, poliomyelitis or radiotherapy, those for whom ascorbic acid supplementation was contra-indicated, women of childbearing age who were pregnant, breastfeeding or not using adequate contraception, were excluded 
Micallef 2009 (Continued)

\begin{tabular}{ll}
\hline Interventions & $\begin{array}{l}\text { Participants were randomised in a } 1: 1: 1 \text { ratio to ascorbic acid } 1 \mathrm{~g},(\mathrm{n}=56) \text {, ascorbic acid } 3 \\
\mathrm{~g}(\mathrm{n}=61) \text { or placebo containing lactose }(\mathrm{n}=62) \text {, all given as a single daily administration } \\
\text { of } 3 \text { hard gelatine capsules for } 12 \text { months }\end{array}$
\end{tabular}

Outcomes

Primary outcome: Charcot-Marie-Tooth neuropathy score (CMTNS) at 12 months after commencement of intervention

Secondary outcomes

1. Muscle strength - QMT

2. Gait velocity - timed 10 metre walk

3. Activity - ODSS

4. Quality of life - Medical Outcomes SF-36

5. VAS for fatigue, pain, cramps and difficulty walking

6. CGI-S

Funding

No indication of funding given

Declarations of interest

One study author (MF) is one of the inventors of the patent for ascorbic acid for the treatment of CMT1A licensed to Murigenetics. Two of the study authors (MF and OB) are scientific advisers to Murigenetics and are $15 \%$ shareholders in the company

Notes $\quad$ Participants were recruited from Sept 2005 to September 2007

\section{Risk of bias}

\begin{tabular}{|c|c|c|}
\hline Bias & Authors' judgement & Support for judgement \\
\hline $\begin{array}{l}\text { Random sequence generation (selection } \\
\text { bias) }\end{array}$ & Low risk & $\begin{array}{l}\text { Block randomisation stratified to site and } \\
\text { sex for subgroup analyses with sequence } \\
\text { generation using an independent contract } \\
\text { research organisation }\end{array}$ \\
\hline
\end{tabular}

Allocation concealment (selection bias) Low risk

Randomisation list sent to an independent research organisation for preparation of ascorbic acid and placebo capsule (identical hard gelatine capsules)

Blinding (performance bias and detection Low risk bias)

All outcomes

Incomplete outcome data (attrition bias) Low risk All outcomes
Ascorbic acid and placebo formulated from hard gelatine capsules (identical in weight, appearance and taste). Placebo contained lactose

Analyses were on an intention-to-treat basis. Reporting of dropouts (total 16) was effective: 6 withdrew ( 1 in placebo, 4 in $1 \mathrm{~g}$ ascorbic acid and 1 in $3 \mathrm{~g}$ ascorbic acid group) due to adverse events (cystitis, myalgia, gastralgia, depression, colitis and insomnia), 2 were lost to follow up ( 1 in 
Micallef 2009 (Continued)

\begin{tabular}{|c|c|c|}
\hline & & $\begin{array}{l}\text { placebo and } 1 \text { in } 3 \mathrm{~g} \text { ascorbic acid group) } \\
, 6 \text { withdrew consent ( } 1 \text { in placebo, } 4 \text { in } 1 \\
\mathrm{~g} \text { ascorbic acid and } 1 \text { in } 3 \mathrm{~g} \text { ascorbic acid) } \\
, 1 \text { was non-compliant with treatment in } \\
\text { the placebo group and } 1 \text { placebo partici- } \\
\text { pant was missing a baseline CMTNS score }\end{array}$ \\
\hline Selective reporting (reporting bias) & Low risk & $\begin{array}{l}\text { All stated primary and secondary outcomes } \\
\text { were fully reported }\end{array}$ \\
\hline Other bias & Unclear risk & $\begin{array}{l}\text { Intention-to-treat analysis meant sufficient } \\
\text { sample size for adequate power. No indica- } \\
\text { tion of how missing data were dealt with for } \\
\text { intention-to-treat analyses. Therefore diffi- } \\
\text { cult to determine risk of bias due to method }\end{array}$ \\
\hline
\end{tabular}

Pareyson 2011

Methods

Parallel, randomised, double-blind, placebo-controlled, multicentre trial

Duration 24 months

Participants

Recruited from 8 Italian hospitals and 1 UK hospital between March 2006 and Sept 2007

354 patients screened for eligibility and 277 eligible patients subsequently randomly assigned to intervention. Six participants did not subsequently receive the allocated intervention and were excluded, leaving intervention 138 (78 women and 60 men) and placebo 133 ( 85 women and $48 \mathrm{men}$ ). All participants had a clinical and genetic diagnosis of CMT1A. Participants were aged between 18 and 70 years and had a CMTNS of between 1 (excluding the electrophysiology component) and 35 (including the electrophysiology component). Exclusion criteria: any cause of neuropathy other than CMT1A; other clinically significant neurological or systemic disease; limb surgery in the 6 months before screening or planned before the final assessment; pregnancy, breastfeeding or planning to become pregnant during the study; receipt of extra-dietary ascorbic acid supplementation in the 3 months prior to screening; any contraindications to ascorbic acid (nephrolithiasis, glucose-6-phosphate dehydrogenase deficiency or iron overload)

Interventions

Ascorbic acid at a dose of $1.5 \mathrm{~g}$ per day as $3 \times 0.5 \mathrm{~g}$ tablets ( 1 at breakfast and 2 at dinner) $(n=138)$ or placebo tablets of identical appearance, taste and smell $(n=133)$

Outcomes

Primary outcome: CMTNS at 12 months after commencement of intervention Secondary outcomes:

Muscle strength - MVIC using hand-held dynamometer for: hand-grip, 3-point pinch, ankle dorsiflexion and plantarflexion

Pain - VAS

Fatigue - VAS

Activity - ONLS, 10 metre walk test, 9-hole peg test

Quality of life - Medical Outcomes SF-36

Interventions for fatigue in peripheral neuropathy (Review)

Copyright @ 2014 The Cochrane Collaboration. Published by John Wiley \& Sons, Ltd. 


\section{Pareyson 2011 (Continued)}

Funding
This trial was supported by Telethon-UILDM (grant numbers GUP04002 and
GUP05007) and AIFA (Grant number FARM53APAH) in Italy, Muscular Dystrophy
Campaign (MDC RA3/736/1), CMTUK, UKMRC and NIHR BRC in the UK
Bracco SpA (Milan) provided ascorbic acid and placebo tablets

Declarations of interest

One of the study authors (RACH) was a consultant for Octopharma, Baxter, Laboratoires Francais de Fractionnement et des Biotechnologies (LFB) and Novartis. One study author (ASo) was a board member of Novartis and received speaker's honoraria from SanofiAventis

Notes

Risk of bias

\begin{tabular}{|c|c|c|}
\hline Bias & Authors' judgement & Support for judgement \\
\hline $\begin{array}{l}\text { Random sequence generation (selection } \\
\text { bias) }\end{array}$ & Low risk & $\begin{array}{l}\text { The randomisation sequence was com- } \\
\text { puter-generated (pseudo-random number } \\
\text { generator) by an independent randomisa- } \\
\text { tion unit }\end{array}$ \\
\hline Allocation concealment (selection bias) & Low risk & $\begin{array}{l}\text { Randomisation sequence known only to } \\
\text { independent unit and the drug dispen- } \\
\text { sary for preparation of identically packaged } \\
\text { ascorbic acid and placebo tablets. Treat- } \\
\text { ment was allocated centrally by telephone } \\
\text { and stratified by centre and disease severity } \\
(\mathrm{CMTNS} \leq 10 \text { versus }>10 \text { or CMTES } \leq 8 \\
\text { versus }>8) \text { with a block size of } 4 \text { unknown } \\
\text { to the investigators in each centre }\end{array}$ \\
\hline
\end{tabular}

Blinding (performance bias and detection Low risk bias)

All outcomes
Participants, treating physicians and physicians assessing outcomes were blinded to treatment allocation throughout study

Missing data for 22 participants who were lost to follow-up were imputed according to Rubin's multiple imputation approach. Reasons for loss to follow-up were reported in full with similar numbers in each group for each reason: 13 participants had adverse events ( 7 in ascorbic acid; 6 placebo), 6 withdrew their consent ( 3 in each group) , 2 in the ascorbic acid group moved away from the study area and 1 in the placebo group left for personal reasons A further 8 participants stopped treatment but did attend follow-up so no imputed 
Pareyson 2011 (Continued)

data were used for these participants

\begin{tabular}{|c|c|c|}
\hline Selective reporting (reporting bias) & Low risk & $\begin{array}{l}\text { All stated primary and secondary outcomes } \\
\text { fully reported at } 24 \text { months }\end{array}$ \\
\hline Other bias & Low risk & None \\
\hline
\end{tabular}

Incomplete outcome data (attrition bias). Summary assessment of risk of bias based on risk of bias associated with unclear description of how missing data was managed in intention-to-treat analysis

CGI-S: Clinical Global Impression Severity Scale

CMT: Charcot-Marie-Tooth

CMTES: Charcot-Marie-Tooth Examination Score

CMTNS: Charcot-Marie-Tooth Neuropathy Score

EQHQ: Euroquol Health Questionnaire

FIS: Fatigue Impact Scale

FSS: Fatigue Severity Scale

GBS: Guillain-Barré syndrome

HADS: Hospital Anxiety and Depression Scale

MVIC: Maximal Voluntary Isometric Contractions

ODSS: Overall Disability Sum Score

ONLS: Overall Neuropathy Limitations Scale

RHS: Rotterdam Handicap Scale

Short Form 36 Health Survey

VAS: visual analogue scale

\section{Characteristics of excluded studies [ordered by study ID]}

\begin{tabular}{l|l}
\hline Study & Reason for exclusion \\
\hline Burns 2009 & RCT of ascorbic acid for CMT1A in children. Fatigue not used as an outcome \\
\hline Carter 2006 & Not a RCT -4 single case series of fatigue reduction associated with modafinil treatment \\
\hline Enderlin 2008 & Not a RCT - observational study of sleep disturbance in multiple myeloma \\
\hline NCT00484510 & No relevant outcomes to be evaluated (only CMT neuropathy score and mRNA). Fatigue not used as an outcome \\
\hline Verhamme 2009 & RCT of ascorbic acid treatment for CMT1A in people under 25. Fatigue not used as an outcome \\
\hline
\end{tabular}

CMT: Charcot-Marie-Tooth; mRNA: messenger RNA; RCT: randomised controlled trial 


\section{Characteristics of ongoing studies [ordered by study ID]}

\section{Attarian 2013}

Trial name or title A phase II randomized, placebo-controlled multicenter clinical trial of three doses of PXT3003 in 80 adult patients with CMT1A treated for 1 year

\begin{tabular}{l|l}
\hline Methods & Randomised double-blind placebo-controlled trial of 12 month intervention \\
\hline Participants & 80 participants between 18 and 65 years with DNA-proven CMT1A \\
\hline Interventions & $\begin{array}{l}\text { 4-arm trial: } \\
\text { liquid doses twice daily of PXT3003 (a new low-dose combination of } 3 \text { already approved drugs (naclofen, } \\
\text { naltrexone and D-sorbitol)). In the highest dose, the active ingredients were } 1 / 0 \text { and } 1 / 100 \text { of the currently } \\
\text { used registered indication dosages. } \\
\text { - } 5 \text { ml liquid doses twice daily of placebo }\end{array}$ \\
\hline
\end{tabular}

Outcomes

Primary objective was clinical and biological safety. Secondary objectives were to obtain preliminary data on clinical and functional outcomes (including CMTNS, ONLS, 6MWT, 9HPT, VAS for fatigue and pain, QMT - hand grip and ankle dorsiflexion and clinical global impression) and electrophysiological parameters (including sensory and motor responses of median and ulnar nerves - NCV, DL and amplitude)

Starting date December 2010

Contact information S Attarian, Hopital La Timone

Notes Primary objective of determining clinical and biological safety achieved. Analyses of secondary outcomes ongoing

\section{NCT00541164}

\begin{tabular}{l|l}
\hline Trial name or title & Effects of coenzyme Q10 on Charcot-Marie-Tooth disease \\
\hline Methods & Randomised, double-blind, cross-over trial with open-label follow-up study \\
\hline Participants & $\begin{array}{l}18 \text { to } 75 \text { years of age with CMT confirmed by medical record review. Regarding weakness, fatigue, and pain, } \\
\text { subjects must report experiencing maximum levels of } 3.0 \mathrm{~cm} \text { or more on the } 10 \mathrm{~cm} \text { visual analog scale (VAS) } \\
\text { for any } 2 \text { of the } 3 \text { symptoms over the past month }\end{array}$ \\
\hline Interventions & $\begin{array}{l}\text { Coenzyme Q10, } 600 \mathrm{mg} / \text { day }(300 \mathrm{mg} \text { twice/day for } 24 \text { weeks) or chewable placebo twice/day for } 24 \text { weeks } \\
\text { followed by the alternative treatment in the cross-over period }\end{array}$ \\
\hline Outcomes & $\begin{array}{l}\text { Primary: changes in weakness, fatigue and pain }(60 \text { weeks) } \\
\text { Secondary: improvements in quality of life }(60 \text { weeks); blood serum levels of the oxidised and reduced forms } \\
\text { of CoQ10 ( } 60 \text { weeks); liver function tests (visits } 1,6 \text { and } 12)\end{array}$ \\
\hline
\end{tabular}

Starting date $\quad$ September 2007 


\section{NCT00541164 (Continued)}

\begin{tabular}{ll} 
Contact information & $\begin{array}{l}\text { Sharon Plank, MD. John P Murtha Neuroscience and Pain Institute, Johnstown, Pennsylvania, United States, } \\
15904\end{array}$ \\
\hline Notes & Study completion date January 2013 \\
\hline
\end{tabular}

NCT02121678

\begin{tabular}{|c|c|}
\hline Trial name or title & Effects of coenzyme Q10 on Charcot-Marie-Tooth disease \\
\hline Methods & Randomised, parallel assignment, open-label \\
\hline Participants & $\begin{array}{l}\text { Aged } 18 \text { to } 80 \text { years with definite or probable CIDP or definite or probable MMN of over } 6 \text { months' duration, } \\
\text { diagnosed according to EFNS/PNS criteria. On stable maintenance dose of intravenous immunoglobulin }\end{array}$ \\
\hline Interventions & $\begin{array}{l}\text { Experimental: run-in - aerobic - resistance } \\
\text { - Week - } 12 \text { to 0: no training } \\
\text { - Week } 0 \text { to } 12 \text { : aerobic training (ergometer bicycle, twice weekly, increasing to } 3 \text { times weekly. } \\
\text { Participants to train at } 60 \text { - } 75 \% \text { of maximal oxygen consumption (VO2-max) for } 30 \text { minutes per training } \\
\text { session) } \\
\text { - Week } 12 \text { to } 24 \text { : resistance training (dumbbells: week } 0 \text { to } 4: 70 \% \text { to } 80 \% \text { of } 1 \text {-repetition max (1-RM); } \\
\text { week } 5 \text { to } 8 \text { : } 75 \% \text { to } 86 \% \text { of 1-RM; week } 9 \text { to } 12: 80 \% \text { to } 92 \% \text { of 1-RM) } \\
\text { Experimental: run-in - resistance - aerobic } \\
\text { - Week - } 12 \text { to 0: No training } \\
\text { - Week } 0 \text { to } 12 \text { : Resistance training (dumbbells as above) } \\
\text { - Week } 12 \text { to } 24 \text { : Aerobic training (ergometer bicycle as above) } \\
\text { For resistance training, participants train unilaterally, the opposite site serves as reference } \\
\text { - MMN participants train elbow and wrist (flexion/extension) } \\
\text { - CIDP participants train knee and elbow (flexion/extension) }\end{array}$ \\
\hline
\end{tabular}

Outcomes Primary (measured at $-12,0,6,12$ weeks or $-12,0,12,18,24$ weeks):

- changes in isokinetic muscle strength

- changes in VO2-max

Secondary (measured at $-12,0,6,12$ weeks or $-12,0,12,18,24$ weeks). Change in the following measures:

- Medical Research Council (MRC)

- change in ODSS

- change in 6-Minute Walk test

- change in Quality of Life measured by The Short Form (36) Health Survey (SF-36) questionnaire

- change in FSS

Starting date April 2014

Contact information Department of Neurology, Aarhus University Hospital. Contact: Henning Andersen, DMSc

Department of Neurology, Rigshospitalet, Copenhagen University Hospital: Contact: Ingelise Christiansen

Notes

Interventions for fatigue in peripheral neuropathy (Review) 
Ramdharry 2011

\begin{tabular}{|c|c|}
\hline Trial name or title & Strengthening hip flexors to improve walking distance in people with CMT disease \\
\hline Methods & Single-blinded, cross-over study. Duration of intervention 16 weeks \\
\hline Participants & 32 participants with CMT disease. Mean age 43.5 (SD 14.76) years with median CMTES of 10 \\
\hline Interventions & 16-week home-based programme of training to increase hip flexor muscle strength \\
\hline Outcomes & $\begin{array}{l}\text { Hip flexor muscle strength measured using fixed myometry at } 4 \text { angles }(0,20,45 \text { and } 90 \text { degrees). Secondary } \\
\text { outcomes of walking endurance, gait speed, exertion, fatigue and general activity not reported in abstract }\end{array}$ \\
\hline Starting date & Not reported \\
\hline Contact information & $\begin{array}{l}\text { Ramdharry GM, MRC Centre for Neuromuscular Diseases, Department of Molecular Neurosciences, UCL } \\
\text { Institute of Neurology, London }\end{array}$ \\
\hline Notes & $\begin{array}{l}\text { Study completed, awaiting authors' reporting of outcomes in full publication prior to next update of systematic } \\
\text { review }\end{array}$ \\
\hline
\end{tabular}

6MWT: 6 metre walk test

9HPT: 9-hole peg test

CIDP: chronic inflammatory demyelinating neuropathy

CMT: Charcot-Marie-Tooth

DL: distal latency

EFNS/PNS: European Federation of Neurological Sciences/Peripheral Nerve Society

FSS: fatigue severity score

MMN: multifocal motor neuropathy

NCV: nerve conduction velocity

ODSS: Overall disability sum score

ONLS: Overall Neuropathy Limitations Scale

QMT: quantitative muscle testing

PMP22 mRNA: peripheral myelin protein 22 (PMP22) messenger RNA

PXT3003: a low-dose combination of naclofen, naltrexone and D-sorbitol

VAS: visual analogue scale 
DATA AND ANALYSES

Comparison 1. Ascorbic acid versus placebo

\begin{tabular}{|c|c|c|c|c|}
\hline Outcome or subgroup title & $\begin{array}{l}\text { No. of } \\
\text { studies }\end{array}$ & $\begin{array}{c}\text { No. of } \\
\text { participants }\end{array}$ & Statistical method & Effect size \\
\hline $\begin{array}{l}1 \text { Change in fatigue }>12 \text { weeks } \\
\text { after commencement of } \\
\text { intervention (measured at } 12 \\
\text { to } 24 \text { months) (VAS } 0-10 \text { or } 0 \\
\text { - 100) }\end{array}$ & 2 & 404 & Std. Mean Difference (IV, Fixed, 95\% CI) & $-0.12[-0.32,0.08]$ \\
\hline $\begin{array}{l}2 \text { Change in } 10 \text { m timed walk > } \\
12 \text { weeks after commencement } \\
\text { of the intervention (measured } \\
\text { at } 12 \text { to } 24 \text { months) }\end{array}$ & 2 & 406 & Mean Difference (IV, Fixed, 95\% CI) & $-0.39[-1.04,0.26]$ \\
\hline $\begin{array}{l}3 \text { Change in speed of completion } \\
\text { of } 9 \text { hole peg test }>12 \text { weeks } \\
\text { after commencement of } \\
\text { intervention (measured at } 24 \\
\text { months) }\end{array}$ & 1 & & Mean Difference (IV, Fixed, 95\% CI) & Subtotals only \\
\hline $\begin{array}{l}4 \text { Change in physical function } \\
\text { score of SF-36 }>12 \text { weeks } \\
\text { after commencement of the } \\
\text { intervention (measured at } 12 \\
\text { to } 24 \text { months) }\end{array}$ & 2 & 400 & Std. Mean Difference (IV, Fixed, 95\% CI) & $0.08[-0.12,0.28]$ \\
\hline $\begin{array}{l}5 \text { Change in mental function } \\
\text { score of SF-36 > } 12 \text { weeks } \\
\text { after commencement of the } \\
\text { intervention (measured at } 12 \\
\text { months) }\end{array}$ & 1 & & Mean Difference (IV, Fixed, 95\% CI) & Subtotals only \\
\hline 6 Serious adverse events & 2 & 450 & Risk Ratio (M-H, Fixed, 95\% CI) & $0.70[0.39,1.27]$ \\
\hline
\end{tabular}

\section{ADDITIONAL TABLES}

Table 1. Data and analysis: amantadine versus placebo

\begin{tabular}{|c|c|c|c|c|}
\hline Outcome & Studies & Participants & Statistical method & Effect estimate \\
\hline $\begin{array}{l}\text { Change in participation } \\
\text { (using the Rotterdam } \\
\text { Handicap Scale) > } 12 \\
\text { weeks after commence- } \\
\text { ment of intervention }\end{array}$ & 1 (cross-over) & 74 & $\begin{array}{l}\text { Mean difference (IV, Fixed, 95\% } \\
\text { CI) }\end{array}$ & $0.31[-0.09$ to 0.72$]$ \\
\hline
\end{tabular}

Interventions for fatigue in peripheral neuropathy (Review) 


\section{WHAT'S NEW}

Last assessed as up-to-date: 5 November 2013.

Date Event Description

18 December 2014 Amended Correction to plain language title

\section{CONTRIBUTIONS OFAUTHORS}

CMW, MG and RCS screened lists of abstracts and titles from electronic and manual searches, CMW and RCS extracted data from included study, CMW prepared first draft of the review and the other authors (PAvD, MPJG and RCS) reviewed the draft. CMW incorporated comments after discussion, where appropriate and the final draft was returned to all authors for approval prior to submission.

\section{DECLARATIONSOF INTEREST}

One author $(\mathrm{CW})$ is currently conducting a single-blind randomised controlled trial of tailored home exercise for people with inflammatory neuropathy (Home exercise for Inflammatory Neuropathy Trial - HINT). The trial is funded by the Guillain-Barré syndrome support group UK (GBSSG). CW is on the Medical Advisory Board of the GBSSG UK. She has no known conflicts of interest.

Pieter A van Doorn (PAvD) and his institution have received consultancy fees from Talecris and CSL Behring for membership of the Scientific board of the ICE trial in CIDP and a scientific board on IVIg in chronic polyneuropathy. PAvD's department has received research grants from Baxter, Sanquin and Talecris: 1. A grant to conduct a RCT comparing IVIg versus IVIg and steroids in GuillainBarré syndrome; 2. A grant to conduct a RCT investigating the effect of a second course of IVIg (SID-trial) in Guillain-Barré syndrome patients with a poor prognosis; 3. A grant to conduct a prospective international study on the effect of a second course of IVIg in Guillain-Barré syndrome patients with a poor prognosis. MPG and PAvD have co-ordinated or conducted one of the trials that was eligible for inclusion in the review (Garssen 2006).

Marcel P Garssen has no known financial conflicts of interest.

Rachel Stockley has no known conflicts of interest.

\section{SOURCES OF SUPPORT}

\section{Internal sources}

- Kings College London, UK. 


\section{External sources}

- No sources of support supplied

\section{DIFFERENCES BETWEEN PROTOCOLANDREVIEW}

Our protocol stated that we would consider trials for inclusion where interventions for fatigue formed part of a multidimensional programme; however, we removed this inclusion criterion.

We removed PEDRO from the list of resources searched.

Use of funnel plots was not appropriate given the small number of studies included.

We revised the potential subgroup analyses, removing age. We also added a definition of 'significant weakness'.

We revised the section Dealing with missing data, which originally stated 'If participant drop out leads to missing data, we shall conduct an intention-to-treat analysis. We shall contact trial authors or sponsors of studies to provide missing statistics such as standard deviations. For dichotomous outcomes, we shall regard participants with missing outcome data as treatment failures and include these in the analysis. For continuous outcomes, we shall carry forward the last recorded value for participants with missing outcome data.' The section was revised since two of the included studies Micallef 2009; Pareyson 2011 undertook an intention-to-treat analysis where missing data were reported. The third study (Garssen 2006) was a cross-over trial that reported reasons for withdrawing participants with missing data effectively, and where data were analysed for the review as the number of participants responding favourably to the intervention versus placebo in either period; imputation of data was not appropriate,

We did an additional search of clinical trials registries, for ongoing trials.

We included more detail in our adverse events outcome, subdividing it into "any adverse events, adverse events which lead to discontinuation of treatment and serious adverse events, which are those which are fatal, life-threatening, or require prolonged hospitalisation."

\section{NDEX TERMS}

\section{Medical Subject Headings (MeSH)}

Amantadine [adverse effects; *therapeutic use]; Ascorbic Acid [adverse effects; *therapeutic use]; Charcot-Marie-Tooth Disease [*complications]; Fatigue [etiology; *therapy]; Guillain-Barre Syndrome [* complications]; Peripheral Nervous System Diseases [complications]; Randomized Controlled Trials as Topic

\section{MeSH check words}

Adult; Child; Humans

Interventions for fatigue in peripheral neuropathy (Review)

Copyright () 2014 The Cochrane Collaboration. Published by John Wiley \& Sons, Ltd. 